\title{
Financing Risk and Innovation
}

\section{Citation}

Nanda, Ramana, and Matthew Rhodes-Kropf. 2017. "Financing Risk and Innovation."

Management Science 63 (4) (April): 901-918. doi:10.1287/mnsc.2015.2350.

\section{Published Version}

doi:10.1287/mnsc.2015.2350

\section{Permanent link}

http://nrs.harvard.edu/urn-3:HUL.InstRepos:35647951

\section{Terms of Use}

This article was downloaded from Harvard University's DASH repository, and is made available under the terms and conditions applicable to Open Access Policy Articles, as set forth at http:// nrs.harvard.edu/urn-3:HUL.InstRepos:dash.current.terms-of-use\#OAP

\section{Share Your Story}

The Harvard community has made this article openly available.

Please share how this access benefits you. Submit a story.

Accessibility 


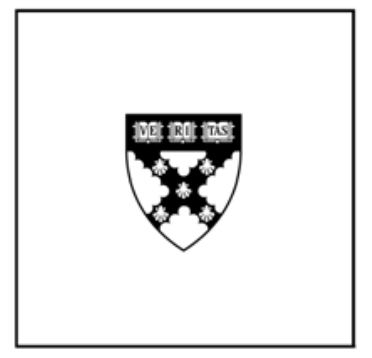

\section{Financing Risk and Innovation}

Ramana Nanda

Matthew Rhodes-Kropf

\section{Working Paper}

\section{1-013}

March 5, 2014 


\title{
Financing Risk and Innovation*
}

\author{
RAMANA NANDA \\ HARVARD UNIVERSITY \\ AND \\ Matthew Rhodes-Kropf \\ HARVARD UNIVERSITY \\ National Bureau of Economic Research
}

Draft: July 17, 2013

\begin{abstract}
We provide a model of investment into new ventures that demonstrates why some places, times and industries should be associated with a greater degree of experimentation by investors. Investors respond to financing risk - a forecast of limited future funding - by modifying their focus to finance less innovative firms. Potential shocks to the supply of capital create the need for increased upfront financing, but this protection lowers the real option value of the new venture. In equilibrium, financing risk disproportionately impacts innovative ventures with the greatest real option value. We propose that extremely novel technologies may need 'hot' financial markets to get through the initial period of discovery or diffusion.
\end{abstract}

JEL: G24, O31

Keywords: Innovation, Venture Capital, Investing, Experimentation, Real Options, Financing Risk

\footnotetext{
* Nanda: Harvard University, Rock Center 221 Boston Massachusetts 02163, rnanda@hbs.edu. Rhodes-Kropf: Harvard University, Rock Center 313 Boston Massachusetts 02163, mrhodeskropf@hbs.edu. We thank Philippe Aghion, Josh Lerner, Andrei Hagiu, Thomas Hellmann, Sam Kortum, Bill Kerr, Praveen Kumar, Robert Marquez, Peter Thompson, Carlos Serrano, Scott Stern, Morten Sorensen, Markus Reitzig, Uday Rajan, David Gaddis Ross, Elena Loutskina, Adriano Rampini, Itay Goldstein and Ulrich Hege for fruitful discussion and comments, and we thank seminar participants at MIT Sloan, ISCTE Business School, Lisbon, World Bank, Tuck School of Business, Queens school of Business, Houston University, University of Lausanne, Notre Dame, Harvard University, Northeastern, Hong Kong University, UT Austin, Darden Entrepreneurship and Innovation Research Conference, Research Symposium on the Economics and Law of the Entrepreneur at Northwestern, HEC Conference on Entrepreneurial Entry, London Business School, Economics of Innovation and Entrepreneurship Conference, European Finance Association meetings, Corporate and Financial Markets Theory Workshop at MIT, Strategy Research Forum, Society for Financial Studies 2011 Cavalcade at Michigan, Western Finance Association, Entrepreneurial Finance and Innovation Conference (Kauffman). All errors are our own.
} 
My attitude is batten down the hatches...Any co without at least a year of cash minimum in the bank is in trouble... - Douglas Leone, a partner at Sequoia Captial in an email to his partner Michael Moritz, October 6th, 2008.

The amount of financing available for startups engaged in innovation is notoriously volatile. These investment cycles have been documented in the literature on venture capital (Gompers and Lerner, 2004; Kaplan and Schoar, 2005; Gompers et al., 2008), but have also been shown in historical work linking financial market activity to radical innovations in manufacturing, communications and transportation going back to the mid 1700s (Kindleberger, 1978; Perez, 2002).

Entrepreneurs and venture capital investors constantly worry about these fluxes in capital and refer to them as financing risk - the potential inability to find future funding for otherwise healthy firms. ${ }^{1}$ This worry seems rational given the great declines in venture investing in both 2001 and 2008, and to a lesser extent the ebbs and flows of capital that have occurred within different venture sectors at different times.

What impact does the shifting supply of capital have on startup innovation? We address this question by modeling the impact of financing risk on the type of new ventures that investors are willing to fund. In our model startups are vulnerable to the state of the capital market every time they choose to raise capital. This leads to a desire to raise capital less frequently and in larger amounts at each stage. However, financiers of such firms want to stage their investments and learn more about the firm's potential before investing further, in order to preserve the real-option to terminate their investment (see Gompers, 1995; Bergemann and Hege, 2005; Bergemann, Hege and Peng, 2008).

The presence of financing risk therefore creates a trade-off for investors between providing more capital and providing less. Investors can reduce the impact of a shock to the financial markets by giving a firm more money upfront (or committing to fund), but in a world with incomplete contracts this comes at the cost of lost abandonment options. $^{2}$ In equilibrium, financing risk therefore has the greatest impact on firms that

\footnotetext{
${ }^{1}$ This is similar in spirit to large firms who finance with debt and face rollover risk when trying to issue new bonds to replace maturing bonds (Acharya, Gale and Yorulmazer, 2011; He and Xiong, 2012b,a).

${ }^{2}$ As we will explore in the body of the paper, in a world of complete contracts financing risk could be eliminated with contracts that guaranteed future funding in the appropriate state. However, in a more realistic scenario of incomplete contracts, investors are unable to appropriately coordinate across time. This leads financing risk to become a salient issue. For example, venture capitalists do use contract terms such as staged financing to attenuate the issue, but since they cannot be written to cover all future financing needs and contingencies this type of contract cannot eliminate financing risk.
} 
have the most option value and cannot be given a lot of money upfront. Firms with the greatest real options are likely to be the most innovative firms in the economy, which is why financing risk has a particularly strong impact on startup innovation.

Our model demonstrates how financing risk impacts the degree to which investors are willing to experiment and thereby change the type of firm that they are able to fund. Our results suggest that financial markets may not simply reduce frictions in the financing for new ventures, but may play a much more vital role in the diffusion and commercialization of new technologies through their ability to facilitate or hinder experimentation by investors. The extent of commercialization of new ideas in a given industry, place, or time may depend crucially on the state of the financial market.

A growing body of work considers the role of finance in the innovation process (see Black and Gilson, 1998; Kortum and Lerner, 2000; Hellmann, 2002; Sorensen, 2007; Lerner, Sorensen and Stromberg, 2011; Tian and Wang, 2011; Manso, 2011; Hellmann and Puri, 2000). We contribute to this line of research by directly considering the cycles of capital availability and their impact on innovation due to the rational response of investors. This is a different way to think about the degree and timing of innovation. Instead of money chasing deals (Gompers and Lerner, 2000), where an abundance of capital leads to the financing of lower return deals, our model suggests that money also changes which deals are funded toward more innovative projects. This leads to a number of new insights and empirical predictions relating to the link between financial markets and the commercialization of innovation. For example, many view the increased failure rates among investments made in boom times as prima facie evidence of lower quality investments. But times of greater experimentation would also be associated with increased failure rates, not because the projects were worse, but rather because they were more novel and unproven. An implication of this alternate view is that we should simultaneously see bigger successes for firms financed in boom times. This matches the findings in Nanda and Rhodes-Kropf (2013) who find that that projects funded in boom times are more likely to fail but conditional on success create more value, patent more and receive more patent cites.

In a similar vein, we contend that increases in investors' willingness-to-experiment may be an important part of the technological revolutions that drive the process of creative 
destruction (Joseph Schumpeter, 1942; Philippe Aghion and Peter Howitt, 1992). Much of the existing literature on the process of creative destruction has focused on the successes of breakthrough technologies at the expense of established firms, while there is little emphasis on tying together the fact that the ultimate success of a few firms commercializing radical innovations comes hand-in-hand with a vast number of failures among other new ventures (Klepper and Graddy, 1990; Kerr and Nanda, 2009). Technological revolutions seem to be associated with periods of greater experimentation, with a few successful new ventures and a large number of failures among startups, not just failures of existing firms.

We demonstrate how financial markets can create this outcome - hot markets facilitate the experimentation that is important for the commercialization and diffusion of radical new technologies. While prior work has suggested that correlations between innovation and financial market booms could be overreaction by investors (Gompers and Lerner, 1998), rational reactions to fundamentals (Gompers et al., 2008; Pastor and Veronesi, 2009), herd behavior for reputation concerns (Scharfstein and Stein, 1990) or even reverse causality (Hobijn and Jovanovic, 2001), our model suggests that at least part of the link between innovation and periods of hot financial markets is because low financing risk leads investors to fund experimentation and hence discover and commercialize the most innovative ideas in the economy. Our model therefore provides a more positive interpretation to peaks of financial activity and may also help explain the historical link between the initial diffusion of many novel technologies (e.g. canals, railways, telephones, motor cars, internet, clean technology) being associated with heated financial market activity (Perez (2002)). Many other predictions arise from our model with implications for how the financial markets impact innovation (Fagnan et al., 2013; Fernandez, Stein and Lo, 2012; Janeway, 2012).

The remainder of the paper is organized as follows. Section I outlines a simple model of investing with financing risk. Section II considers the investor response to financing risk and shows why why the most innovative projects in the economy are most impacted by financing risk. Section III summarizes the key implications and extensions of our model and Section IV concludes. 


\section{A Model of Investment}

The central goal of our model is to delineate the equilibrium impact of financing risk on investment decisions. Financing risk is the risk that future investors will not fund a firm at its next stage even if the NPV of the project, if fully funded, has not changed, leading a viable firm with good fundamentals to go bankrupt. We emphasize that financing risk is part of a rational equilibrium and show why innovative projects are particularly susceptible to financing risk.

We proceed in two steps. First, we outline a simple model of financing risk to highlight the conditions under which investors would either invest or not invest in the same firm, depending on their beliefs about funding availability for startups in the next period. Next, we endogenize the response to the potential of financing risk to document that it can be eliminated for many firms, but not for the most innovative startups in the economy.

\section{A. Setup}

We model a single early stage firm inside a broader economy. By early stage we aim to capture the idea that the firm does not have the cash flows to be self sufficient and hence requires outside investment to survive. A second aspect of early stage firms is that investment in an early stage firm may produce positive results, negative results or inconclusive results, so more money may be needed to learn if the project is viable. For example, a new biotech firm may do initial studies to determine how well a compound works in mice. Then, depending on the results, money may be spent to start primate trials, the project may be shut down, or more studies on mice may be needed.

Consider a firm that must get over hurdles in order to reach its potential expected payoff, which one can think of as the exit point for investors. These hurdles could represent several rounds of technological uncertainty, or customer adoption risk, or scaling issues, etc. For simplicity we will examine a firm with just a single hurdle as this is enough to demonstrate the relevant issues.

The firm needs to raise $x$ from an investor to attempt to get over the hurdle. The investor will only fund the firm if it is an NPV positive investment. We will refer to the NPV of a firm before it crosses the hurdle as $\Pi_{t}$, where the $t$ subscript indicates the period. With a probability $\gamma_{l}$ the results are negative and the project fails, where the $l$ 
subscript represents loss. Failure means that some information is learned about the firm that makes any new investment negative NPV regardless of the financing environment. It might be the case that its technology does not work, its new processes is not cost effective or estimates of the target market are smaller than initially hoped, etc. With probability $\gamma_{a}$ the firm meets a potential acquirer and negotiates an exit price, where the $a$ represents an acquisition (this will be elaborated on below). With probability $\gamma_{w}$ the project wins, achieves the hurdle, and gets a payoff of $W$ which one can think of as IPO or cash-flow-positive NPV. And with probability $1-\gamma_{l}-\gamma_{a}-\gamma_{w}$ the project needs more money to attempt to get over the hurdle again. In this case spending $x$ again gives the firm another attempt to get over the hurdle. Entrepreneurs and investors often refer to this state of neither complete failure nor successfully overcoming the hurdle as the act of 'pivoting' to try to cross the hurdle again. For simplicity we suppress $\gamma_{w}$ (assume $\gamma_{w}=0$ ) as an alternative exit is not relevant and we focus only on the potential acquisition.

At each point in time the possibility that the firm needs more money means that, in theory, a firm could continue for a nearly infinite number of periods. However, we would never expect to actually see this in the data. For example a firm with a $33 \%$ chance of needing more money each period would only have an $11 \%$ chance of neither making it over the hurdle or failing after two periods and only a $0.4 \%$ chance after 5 periods. The notion that it may always be possible to try for one more period captures the idea that while at the start of a project investors can be confident that the project will yield a positive or negative result within about 7 years, they can never be sure how much money the project will require. Thus, conditional on a firm making it 7 years without failing or succeeding investors cannot be sure how much more investment will be needed to get an answer one way or the other.

We model the decision of financiers willing to invest in early stage firms, which we call venture capitalists (VCs). ${ }^{3}$ In each period, perfectly competitive VCs choose whether or not to invest the $x$ to support the firm through the next period. Firms that do not receive capital go bankrupt and, for simplicity, are worth nothing. Initially we will consider VCs

\footnotetext{
${ }^{3}$ This is consistent with the view that VCs are thought to have a number of skills relating to the finding and nurturing new companies (Hsu (2004); Kaplan, Sensoy and Stromberg (2009); Hellmann and Puri (2002); Sorensen (2007)). However, our notation of VC could represent any investor in such firms. For example, Lamoreaux and Sokoloff (2007) show how even as early as 1900 private individuals acted as VCs and funded innovative new ventures.
} 
who can fund the firm for only one period, and later we consider larger investments. ${ }^{4}$ However, capital is never scarce in the model. Although each individual VC is capital constrained, we assume that there are enough VCs so that all positive NPV projects can get done. These assumptions maximize the chance that the $\mathrm{VC}$ will invest as we want to make sure our results do not arise from any aggregate capital constraints.

VCs require an expected rate of return of $r .{ }^{5}$ VCs are rational and use a positive NPV rule for investing and they expect other VCs to also rationally use a positive NPV rule. Since VCs compete away all rents leaving the entrepreneur with any positive NPV, a VC investing in period 1 gets a fraction $x /\left(\Pi_{1}+x\right)$ of the firm. ${ }^{6}$ This fraction is then diluted down in the next period as the next investor gets a fraction of $x /\left(\Pi_{2}+x\right)$, so the first investor retains the fraction $x /\left(\Pi_{1}+x\right) *\left(1-x /\left(\Pi_{2}+x\right)\right)$. Of course, the present discounted value of the VCs' fractions in each future period times the expected payoff in each future period exactly equal $x .^{7}$ This ensures that the firm will get an investment as long as the firm is not NPV negative. Therefore, as we proceed, in order to determine if the VC will invest we will simply need to determine if the firm is not NPV negative.

\section{B. Forecasts}

A key aspect of our model is the sequential investments that may be required before the firm becomes cash flow positive. Thus VCs deciding whether to invest must determine whether or not they believe other investors will continue to support the firm in the future (independent of the fundamental performance of the firm). Note, however, that for an equilibrium to be rational all forecasts of behavior must be correct in expectation.

We assume that there is an exogenous, publicly observable signal that investors use to

${ }^{4} \mathrm{VCs}$ have limited pools of capital and are often further restricted by the contract with their limited partners to invest no more than a given percent in any one deal.

${ }^{5}$ Pastor and Veronesi (2009) provide an interesting explanation of asset price increases and decreases in innovative sectors based on changing discount rates. Our focus is on real activity in innovative sectors and the changing nature of that activity.

${ }^{6}$ Nothing is driven by the choice of equity contract and the model will work with any contract, including a one period debt contract, because the firm today is still impacted by the potential not to receive the funding (no matter the type of contract) tomorrow.

${ }^{7}$ For example consider a simple firm that requires an investment of $\$ 1$ but pays $\$ 4$ with a $50 \%$ probability or zero. If it pays zero then another $\$ 1$ investment will pay $\$ 4$ with a $50 \%$ probability and with a $50 \%$ probability the firm ends. The NPV of the firm, $Y=0.5 * 4+0.5 *(0.5 * 4-1)-1=2+0.5-1=\$ 1.50$, is captured by the entrepreneur. Therefore, the VC who invests the first $\$ 1$ gets $1 /(Y+1)=1 / 2.5=2 / 5$. The NPV of the second investment $\$ 1$ is $Z=0.5 * 4-1=\$ 1$, so the $\mathrm{VC}$ who invests the second $\$ 1$ gets $1 /(Z+1)=1 / 2$ of the firm. If the second investment occurs, then the first VC who originally owned $2 / 5^{t h}$ of the company gets diluted down to $1 / 5^{t h}$. Thus the first VC gets an expected payoff of $0.5 * 4(2 / 5)+0.5 * 0.5 * 4(1 / 5)=0.80+.20=\$ 1$ which is exactly what he invested. Therefore, the investment including expected dilution is NPV zero for the VCs. This ensures a VC will invest as long as the firm has NPV $\geq 0$, i.e., the fraction $x /(N P V+x)$ is less than or equal to 1 . 
form beliefs about whether other investors will invest in the next period. We will delineate the signal with $s(t) \in[0,1]$. The signal has an exogenous transition probability that we assume follows a Markov chain. $\theta$ is the probability that the signal stays in state 1 , and $(1-\theta)$ is the probability that the signal shifts from 1 to $0 . \phi$ is the probability that the signal shifts from 0 to 1 , and $(1-\phi)$ is the probability that the signal stays in state 0 . Thus, the transition matrix for the signal $s(t)$ is

$$
\begin{gathered}
s(t+1)=1 \\
s(t)=1 \\
s(t)=0
\end{gathered} \quad\left[\begin{array}{cc}
\theta & 1-\theta \\
1-\phi & \phi
\end{array}\right]=S
$$

The VCs use $s(t)$ to form beliefs about the actions of other VCs investing in the future. When $s(t)=1$ the forecast is that in the next round, $(t+1)$, other VCs will invest with probability $\theta$ (that is, when $s(t+1)=1$ ), and not invest with probability $1-\theta$. When $s(t)=0$ the next round VCs are forecasted to invest with probability $1-\phi$ and not to invest with probability $\phi$. These beliefs must be correct in equilibrium for them to be rational - this will be demonstrated below.

We model the transition probability as exogenous because we are interested in the response of investors to the possibility of financing risk rather than in the causes for the potential equilibria switch. ${ }^{8}$ However, one can think of exogenous shocks to fundamentals that determine which signal occurs and thus which equilibrium results. We will refer to a 'shock' as a shift between states. Examples of such shocks might relate to an increase in uncertainty that causes firms to temporarily pause their investing activity Bloom (2009). Alternatively, we might think of these shocks as relating to a key invention in a sector such as bio-tech, green-tech, or high-tech, a change in future industry growth expectations or a government proposal to improve technology in an area.

\footnotetext{
${ }^{8}$ The global games literature started by Carlsson and van Damme (1993), and used in interesting papers such as Morris and Shin (1998) and Goldstein and Pauzner (2004) allows the user to create and alter parameters that affect which of multiple equilibria holds. It is useful for demonstrating theories about when and why the equilibrium may jump. However, we take the shock to be exogenous because we are interested in looking at the investors' response given the jump rather than focusing on the reasons for the jump.
} 


\section{Exit values}

The final aspect of the setup defines the relationship between the signal and exit value. In our setup, firm exit value will depend on the future financing environment or signal. In appendix A.A1 we formally demonstrate how equilibrium negotiations in an acquisition are impacted by a poor financing environment. The intuition is that lower outside options for the target, and lower competitive pressures for the acquirer, in the event that negotiations fall through, reduce the target's bargaining power if alternative funding has dried up. ${ }^{9}$ Embedding this in the model changes no results and so for simplicity we assume a reduced form exit value that depends on next periods signal, $V(s(t+1))$.

The future value of the firm, therefore, is $V(s(t+1))$, where $V(1)>V(0)$ if a signal in period $t+1$ of 1 will result in investment and a signal in period $t+1$ of 0 will result in no investment. However if investors will always invest or never invest, independent of the signal, then $V(1)=V(0)$.

\section{Equilibrium}

We hypothesize (and later confirm) that there are at least two symmetric pure strategy subgame perfect Bayesian equilibria - one in which VCs choose to fund a viable project and one in which they do not. ${ }^{10}$ The existence of a rational expectations equilibrium boils down to a fixed point mapping, where the first step is a state-contingent mapping of every individual's belief (about the actions of other players) to his own action. The second step is a state-contingent mapping of all individual actions onto the individual belief vectors.

Our equilibria will be similar to the "sunspot equilibria", see Chatterjee, Cooper and Ravikumar (1993). ${ }^{11}$ However, we extend this idea as our equilibria are across time -

\footnotetext{
${ }^{9} \mathrm{~A}$ signal that results in the belief that investors are less likely to invest next period, $s(t)=0$, could alternatively reduce the value of the firm today if, for example, nervous employees reduced effort or looked for other jobs, or customer's delayed purchases, or other channels. We present the main idea with an acquisition channel but other ideas would reinforce our findings.

${ }^{10}$ Note that since no information is hidden nothing is learned from off equilibrium path actions. An investor who sees a negative NPV investment made does not alter his belief in the probability of future investment because VCs are assumed equally informed and each VC is small enough that their effect of the aggregate probability of funding is negligible. Equilibria are thus invariant to small fluctuations in the behavior of any one player.

${ }^{11}$ See also Diamond (1982), Cooper and John (1988)), and the big push literature (see Murphy, Shleifer and Vishny (1989), and a review by Matsuyama (1995)). In this work and in Shleifer (1986), positive externalities between investments create the possibility of both a low and a high equilibrium that depends on the self-fulfilling expectations of investors. However, in our paper there are no externalities between investments and instead it is the required coordination between investors across time on the same investment that creates the possibility that an exogenous shock to financial markets can cause rational investors to stop investing in a way similar in spirit to Acharya, Gale and Yorulmazer (2011).
} 
beliefs are about the actions of future players rather than about other players' simultaneous actions. That said, what is interesting about our work is not that we can create "sunspot equilibria" but that we show how investors in different types of projects respond to and prepare for these potential shocks.

Since all VCs are rational they will invest if the expected NPV of the project is positive. Let $\left.\Pi_{t}\right|_{s(t)=1}$ represent the NPV of the project when the signal is 1 and let $\left.\Pi_{t}\right|_{s(t)=0}$ represent the NPV of the project when the signal is 0 . Recall that for now each VC only has enough money to support the project for one period and we are not yet allowing them to pool together or increase their investment in response to the potential financing risk. The extensive form of the game is shown in figure 1.

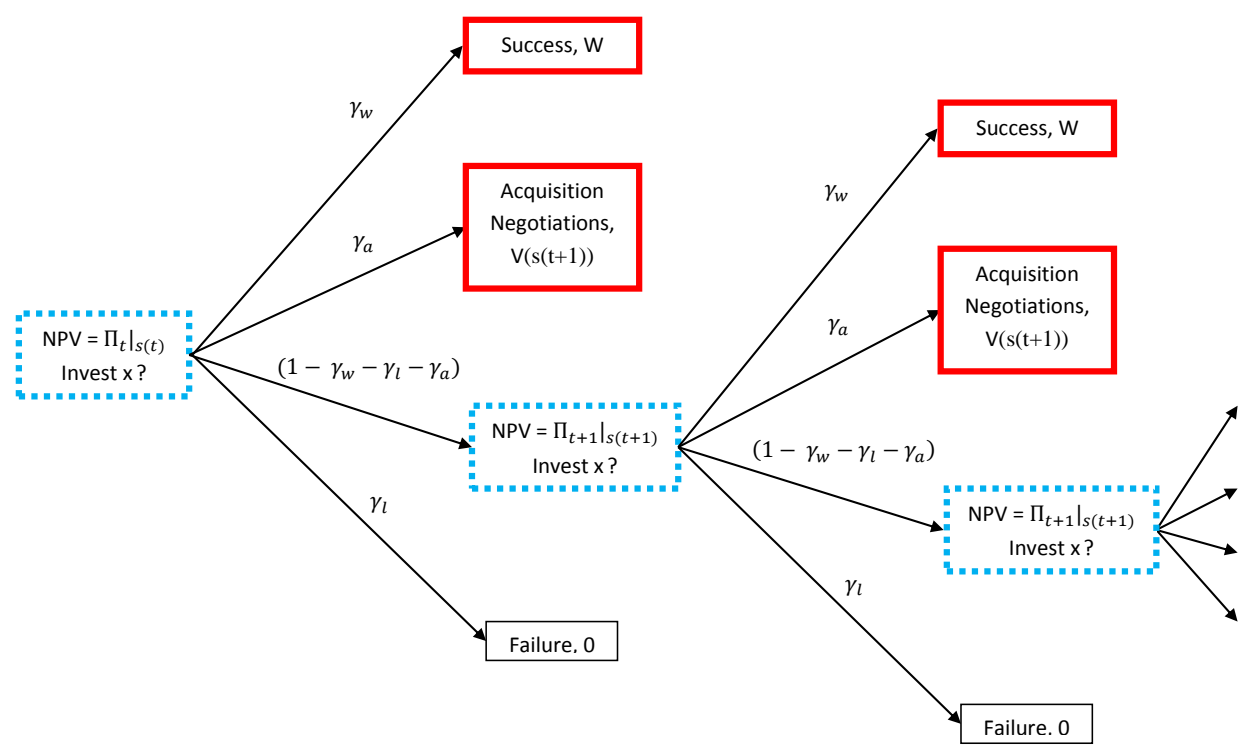

Figure 1. Extensive Form Representation of the Model

Conditional on a rational forecast of the VCs' actions in the future, each investor maximizes their wealth, and the NPV of the project in period $t$ can be written as

$$
\begin{aligned}
\left.\Pi_{t}\right|_{s(t)}=\frac{1-\gamma_{l}-\gamma_{a}}{1+r}\left[\left.Z \Pi_{t+1}\right|_{s(t+1)=1}+Y \max \left[\left.\Pi_{t+1}\right|_{s(t+1)=0}, 0\right]\right] \\
+\frac{\gamma_{a}}{1+r}[Z V(s(t+1)=1)+Y V(s(t+1)=0)]-x
\end{aligned}
$$

where $Z=s(t) \theta+(1-s(t))(1-\phi)$ and $Y=s(t)(1-\theta)+(1-s(t)) \phi$. Note that if 
$\left.\Pi_{t+1}\right|_{s(t+1)=0}<0$ then the future VCs will not invest if the signal is zero and the max ensures they earn zero in this case rather than a negative amount. ${ }^{12}$

The above equation demonstrates the effect of the forecast of the $\mathrm{VC}$ on the current NPV. Comparing equation (2) when $s(t)=1$ to the same equation when $s(t)=0$ we see that the NPV when the current signal is zero may be impacted in two ways. First, if the firm neither exits nor fails and if investors believe that future investments will only get done if $s(t+1)=1$, then $s(t)=0$ lowers the chance of accruing value from all future investments because $\left.\Pi_{t+1}\right|_{s(t+1)=1}$ is now multiplied by $(1-\phi)$ which is less than $\theta$. Second, if investors believe that future investments will only get done if $s(t+1)=1$, then $V(s(t+1)=1)>V(s(t+1)=0)$, so that the signal impacts firm value in the event of a negotiation. This is because the probability of getting the higher value, $V(s(t+1)=1)$ is believed to be less when $s(t)=0$, since $(1-\phi)$ is less than $\theta$.

Exploiting the stationarity in the model, $\left.\Pi_{t}\right|_{j}=\left.\Pi_{t+1}\right|_{j}$, we can solve for the expected NPV if investors believe that if $s(t+1)=0$ then future investors will not invest:

$$
\begin{array}{r}
\left.\Pi\right|_{s(t)}=\left[s(t)+(1-s(t)) \frac{(1-\phi)\left(1-\gamma_{l}-\gamma_{a}\right)}{1+r}\right] \frac{\gamma_{a}[\theta V(1)+(1-\theta) V(0)]-x(1+r)}{(1+r)-\theta\left(1-\gamma_{l}-\gamma_{a}\right)} \\
+(1-s(t))\left[\frac{\gamma_{a}[(1-\phi) V(1)+\phi V(0)]}{1+r}-x\right] .
\end{array}
$$

This is the key equation because it incorporates how the beliefs impact the investors expected NPV. ${ }^{13}$ This leads directly to our understanding that the shock can result in a funding failure for some, but not all, firms.

PROPOSITION 1: Given the belief that $s(t+1)=0$ means no future investment and $s(t+1)=1$ implies future investment, firms can be grouped into three categories of funding equilibria:

- If $\left.\Pi\right|_{s(t)=0} \geq 0$ investors always fund the firm even if $s(t)=0$.

- If $\left.\Pi\right|_{s(t)=1}<0$. investors never fund the firm even if $s(t)=1$.

\footnotetext{
${ }^{12}$ Recall that for simplicity we suppress $\gamma_{w}$ (assume $\gamma_{w}=0$ ) as an alternative exit is not relevant and we focus only on the potential acquisition.

${ }^{13}$ We can, of course, also solve for the expected NPV if investors believe that if $s(t+1)=0$ then future investors will invest, which is just the standard NPV calculation $\frac{\gamma_{a} V-x(1+r)}{r+\gamma_{l}+\gamma_{a}}$. Note that V is not a function of a signal because if the project is believed to receive funding even after the bad signal then $\mathrm{V}$ is the same with either signal.
} 
- If $\left.\Pi\right|_{s(t)=1} \geq 0>\left.\Pi\right|_{s(t)=0}$ then there are two symmetric pure strategy subgame perfect Bayesian equilibria (given the beliefs), one in which investors invest when $s(t)=1$, and the second in which investors do not invest when $s(t)=0$.

Firms whose funding depends on the signal have parameter values such that $\gamma_{a}[\theta V(1)+$ $(1-\theta) V(0)]>x(1+r)$ and

$$
\frac{\gamma_{a}[\theta V(1)+(1-\theta) V(0)]-x(1+r)}{(1+r)-\theta\left(1-\gamma_{l}-\gamma_{a}\right)}<\frac{x(1+r)-\gamma_{a}[(1-\phi) V(1)+\phi V(0)]}{(1-\phi)\left(1-\gamma_{l}-\gamma_{a}\right)} .
$$

\section{PROOF:}

See Appendix A.A3

It is only rational for a $\mathrm{VC}$ to forecast that a future $\mathrm{VC}$ will invest if it is an NPV positive investment, $\left.\Pi\right|_{s(t+1)=1} \geq 0$. On the other hand, it is only rational to forecast other VCs will not invest if $\left.\Pi\right|_{s(t+1)=0}<0$. Therefore, for the shock to have impact it must be the case simultaneously that $\left.\Pi\right|_{s(t+1)=1} \geq 0$ and $\left.\Pi\right|_{s(t+1)=0} \leq 0$. Thus, a firm that is 'good enough' (high enough $V(1)$ or $\gamma_{a}$, for example) will get funded whether or not the shock occurs. In this case a forecast of no funding is not rational. For other 'weak' firms the firm never receives funding as it is always NPV negative. But there are some firms where the shock is important because when future funding is less likely the firm NPV drops from positive to negative. For these firms, $\phi$ must be large enough such that the shock is not forecast to end so quickly that it is always NPV positive to keep investing through the 'bad' (low signal) times. If it is then firms are not affected by the shock. Essentially, inequality (4) says that if $s(t)=0$, the gain that may occur if the signal switches back to 1 must be less than the cost of of keeping the firm alive in 'bad' times.

For the shock to be important, the project must change from positive to negative NPV in period $t$ based on the (rational) forecast for funding availability in $(t+1)$. This is not as straight forward as it sounds. For example, if the 'project' is simply a series of NPV positive coin flips then failing to get funding tomorrow will reduce the total NPV of the project, however, it will still be positive NPV. Thus, the investor today should still pay to see the coin flipped, and so should the investor tomorrow thus making the forecast of no future financing incorrect. The only way for a 'no-invest' forecast to be correct is if the 
forecast fundamentally alters today's payoffs. Appendix A.A2 demonstrates why a model in which investors simply forecast the potential not to receive funding and thus lose the future project payoffs cannot rationally contain financing risk.
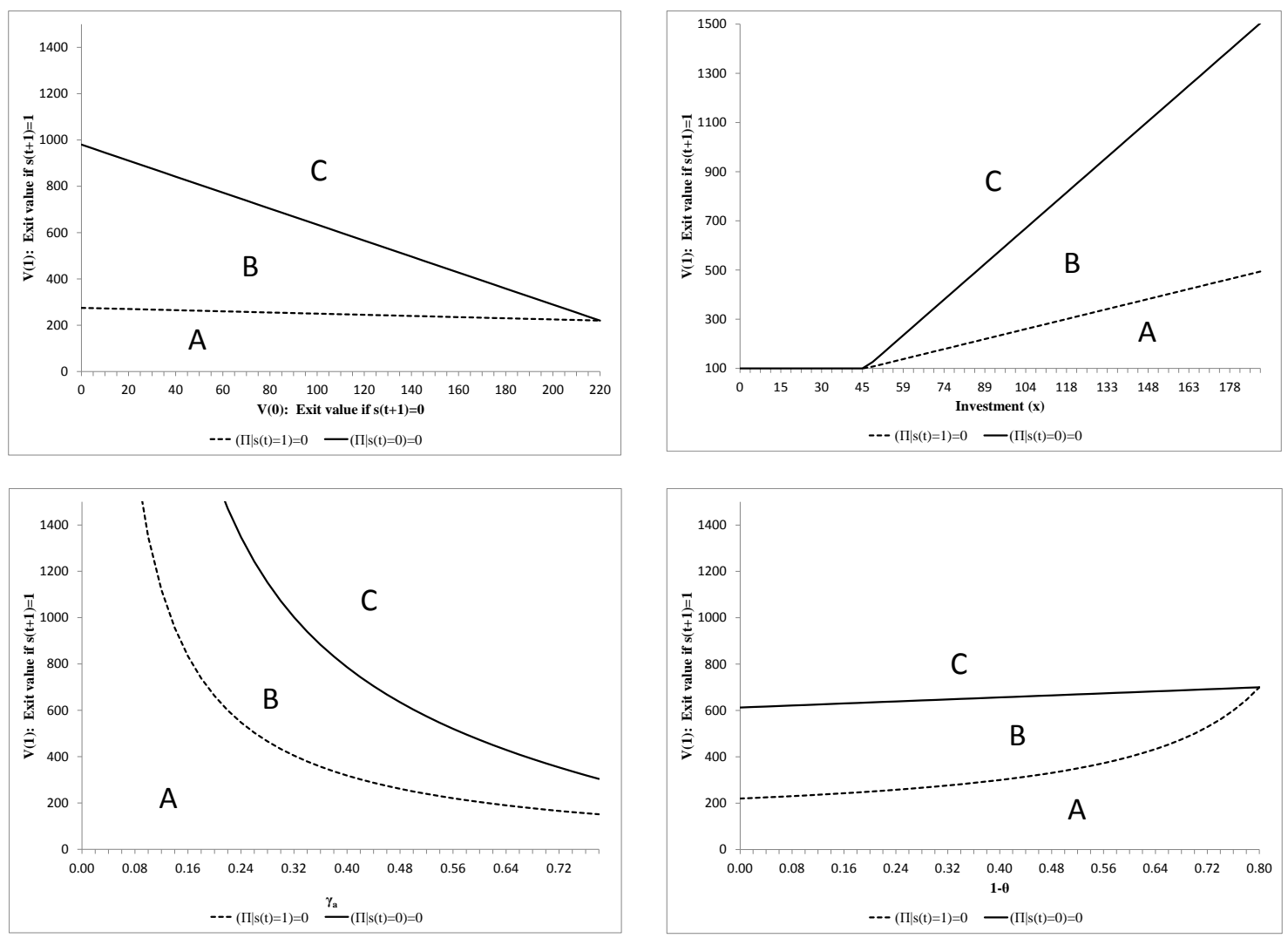

Figure 2. Equilibrium Regions - In all graphs the paramatures that are not graphed take the following values $V(0)=100, V(1)=300, x=100, r=0.1, \theta=0.8, \phi=0.8, \gamma_{a}=0.5, \gamma_{l}=0.2$

Figure 2 graphs the three regions to provide more intuition about the tradeoffs. In the top left we document how the relative difference between $V(1)$ and $V(0)$ relate to the three funding equilibria we outline above (holding other parameters constant). The lower dashed line traces out the points for which $\left.\Pi\right|_{s(t)=1}=0$. Firms above the dashed line get funding when $s(t)=1$. All points below this line are ones for which $\left.\Pi\right|_{s(t)=1}<0$. That is, firms in region $\mathrm{A}$ are so weak that they do not receive funding even if $s(t)=1$. These are firms that never receive funding. The bold line traces out the points for which $\left.\Pi\right|_{s(t)=0}=0$. Firms above the bold line in region $\mathrm{C}$ get funding even when $s(t)=0$. That 
is, these firms are so good that they receive funding even if $s(t)=0$. Region $\mathrm{B}$, below the bold line and above the dashed line, is of particular interest. Firms in region B are ones that are funded when $s(t)=1$ (since they are above the dashed line) but do not get funding if $s(t)=0$ (since they are below the bold line). These firms are susceptible to financing risk as their funding is contingent on the state. The graph shows an intuitive point. As $V(0)$ (the baseline value the firm gets in an acquisition even if $s(t+1)=0$ ) increases, the firm does not need to have a significantly higher $V(1)$ in order to always be financed. That is, financing risk is more salient for firms where $V(0)$ is relatively low. These firms will be particularly susceptible to financing risk unless $V(1)$ is so high that the expected value of funding the firm in always NPV positive.

The top right of Figure 2 plots $V(1)$ against $x$. Note that the $\mathrm{Y}$ axis is truncated at 100 because in this graph $V(0)$ has been set to 100 and hence any $V(1)$ below 100 is not economically viable. As with the top left graph, firms in region A are never funded, firms in region $\mathrm{C}$ are always funded, those in region $\mathrm{B}$ are funded with $s(t)=1$ but not funded when $s(t)=0$. This figure highlights that as $x$ rises, the expected loss from continuing to invest in the event that $s(t+1)=0$ becomes more significant, making more firms unlikely to be funded. This is true even when $s(t)=1$ since there is a $1-\theta$ chance that $s(t)=1$ transitions to $s(t+1)=0$. Although a higher $V(1)$ counters this effect, the graph points out that the implications of a shock are much more important when $x$ is high. This is consistent with biotechnology and clean-technology venture capital investors being much more concerned about financing risk than VCs who funded consumer internet startups.

The lower left of Figure 2 plots $V(1)$ against $\gamma_{a}$. As the $\gamma_{a}$ approaches 0 , that is the probability of ever being acquired approaches 0 , startups become unviable. In this example $\gamma_{l}$ has been set to 0.2 , so that $\gamma_{a}$ cannot be greater than 0.8 . The reader may wonder why the bold and dashed line do not cross when $\gamma_{a}=0.8$. This is because even though the firm will either be acquired or fail, the expected value when acquired is a function of the state.

The lower right of Figure 2 plots $V(1)$ against $1-\theta$. It shows that as $1-\theta$ increases, firms require a higher $V(1)$ to get funded. This is because a higher $1-\theta$ increases the likelihood that a shock will occur leading future investors not to invest. In this chart, $\phi$ has been set to 0.8 . Since by construction, $s(t)=1$ leads to a higher forecast of a good 
funding equilibrium, it must be the case that $\theta<1-\phi$ or alternatively that $1-\theta<\phi$. Since $\phi$ is set to 0.8 , in this example, the two lines cross at 0.8 . This is the point at which firms are equally impacted by the signal, since the forecast of $s(t+1)=0$ is the same for both $s(t)=0$ and $s(t)=1$. Consistent with this argument, the region to the right of $1-\theta>0.8$ does not make economic sense in this example as it would lead to cases where firms are not funded when $s(t)=1$ but are funded when $s(t)=0$.

While the charts above plot $V(1)$ against different parameters, another way to examine the equilibria for different projects is to see how the NPV of the project varies as financing risk goes up. In equilibrium different types of projects are impacted by financing risk in different ways. Figure 3 shows how the NPV of different projects changes as financing risk, $(1-\theta)$, gets larger. Project 1 is unaffected by financing risk because it is so high quality that it can get funded even after a shock. Projects 3 and 4 become less valuable as financing risk increases, with project 4 actually becoming NPV negative if financing risk is high enough. Project 2 is interesting because for low levels of financing risk it is unaffected by the shock but eventually for high enough financing risk (i.e. high enough probability of a shock) its value falls to the point where it will not get funding in the bad state and so its NPV falls and continues to decrease with greater financing risk.

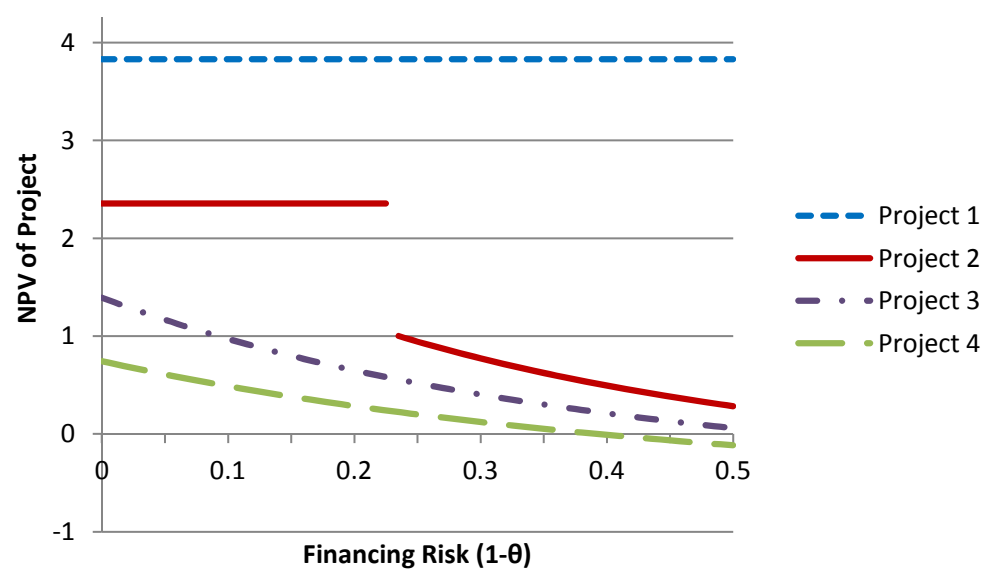

Figure 3. NPV and Financing Risk

Although it is a relatively unique case, it is instructive to understand why the equilibrium NPV for project 2 jumps down. Figure 4 shows why. Remember that in equilibrium financing risk is only rational if the forecast that investors will not invest in 


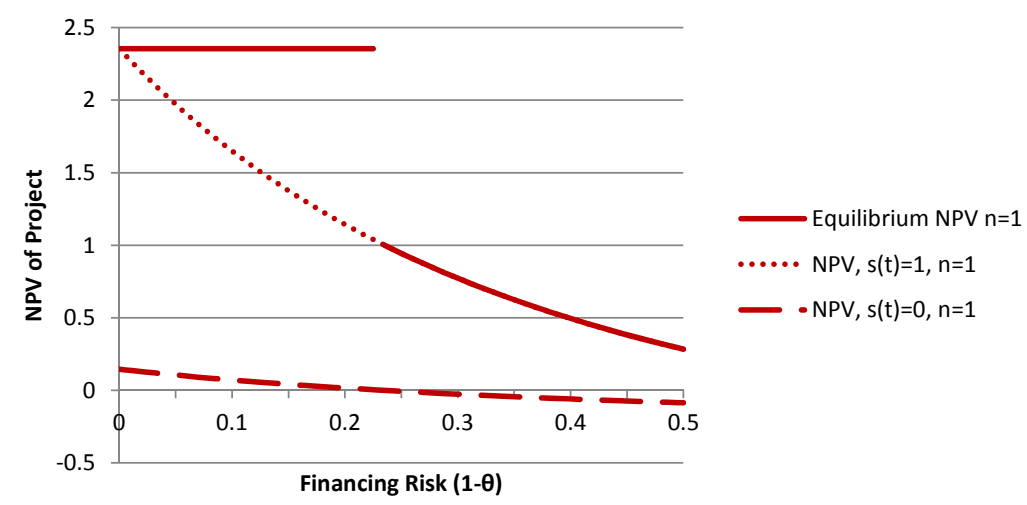

Figure 4. Equilibrium NPV

the bad state is rational. It is only rational for investors to not invest in the bad state if the project is NPV negative in that state. In Figure 4 the lowest line (large dashes) is the NPV of investing when the forecast is for less likely future funding $(s(t)=0)$. However, for low enough financing risk the NPV is actually positive even when the investor believes (wrongly) that future funding is unlikely. In fact, since the NPV is positive whether or not the investor believes future investors are likely to invest, the current investor should invest regardless of the signal and so will future investors. Thus, Project 2 , is initially unaffected by financing risk. Eventually, however, the forecast that future investors will not invest if $s(t+1)=0$ becomes correct and the NPV, even in the good state, is impacted by the possibility of a future jump to the bad state, i.e., it is impacted by financing risk.

We have presented the equilibrium with financing risk but no exante preparation for the potential shock. In the next section, we examine what happens if everyone expects both a possible shock as well as a potential subsequent shock back to the high funding state. Then we consider the equilibrium investor response to the threat of financing risk.

\section{Investor response to financing risk.}

Given financing risk, we must ask how investors respond to the potential risk, because their response could eliminate the impact of the shock for some investments. We do so in three steps. First, if the reliance on other investors is what leads to the problem, the question arises as to whether a VC with more money or a syndicate of VCs can overcome the no-invest equilibrium. We show this is not the case. Second, we include the 
possibility that investors can write complete contracts that cover future financing needs. This demonstrates the optimal response in a perfect world. Finally, we consider a world in which contracts are incomplete. It is this set up that demonstrates the trade-offs faced by investors attempting to fund experimental projects.

\section{A. Can a wealthier investor protect their investment from a shock?}

Consider a VC who has enough capital to fund the investment for two periods. One might imagine that this $\mathrm{VC}$ is less impacted by financing risk in the first period they invest because they can be sure to invest in the next period. In this case one might think that if $s(t)=0$, the expected value of the firm in the first period is

$$
\left.\Pi_{t}\right|_{s(t)=0} ^{n=2}=\frac{1-\gamma_{l}-\gamma_{a}}{1+r}\left[\left.\phi \Pi_{t+1}\right|_{s(t+1)=0}+\left.(1-\phi) \Pi_{t+1}\right|_{s(t+1)=1}\right]+\frac{\gamma_{a}}{1+r} V(1)-x
$$

where the $n=2$ superscript signifies that the firm has two periods of funding. This NPV is equation (2) with $s(t)=0$ but a guaranteed extra round of investment that will occur independently of next rounds signal (because of the second $x$ held by the VC). This would suggest both that the investor gets $\left.\Pi_{t+1}\right|_{s(t+1)=0}$ (which is negative) instead of zero because of the extra funding, and that firm value is improved from as there is no longer a chance of getting $V(0)$ after the first investment. If this were correct, then the NPV in period $\mathrm{t}$ might be greater for a $\mathrm{VC}$ with enough funding for two periods.

However, backward induction applied to equation (5) demonstrates the fallacy of this argument. Suppose that $s(t+1)=0$ and the VC needs to decide whether to invest her second $x$ in a firm where the NPV depends on the signal. At this point, since she only has one $x$ left, her investment decision is identical to the case where she only had one $x$. The NPV for her investment is $\left.\Pi_{t+1}\right|_{s(t+1)=0}$. However, the expectation of no future investment is only rational if $\left.\Pi_{t+1}\right|_{s(t+1)=0}<0$. Therefore, the VC will not invest her second $x$ because it is an NPV negative investment. Of course, using backward induction, the $\mathrm{VC}$ will realize that she will not invest the second $x$ if $s(t+1)=0$, and therefore, will reevaluate her decision to invest the first $x$. Since the second $x$ will only be invested when $s(t+1)=1$, the only time that the $\mathrm{VC}$ would invest her second $x$ is when others would invest anyway. Hence, the decision to invest the first $x$ is the same for VCs with either $x$ or $2 x$. 
This same logic applies even if we consider the possibility that a VC has more than $2 x$. To see this, note that the very last $x$ that the $\mathrm{VC}$ has will only be spent if there is a positive signal in that period. The VC also knows that if the 'good' signal has not occurred in the period just before this last period, then $1-\phi$ is not large enough to make investing the second to last $x$ a good idea (if it were large enough, it would cause VCs to behave as if the state occurs today and hence have caused them to not be impacted by the initial shock). Therefore, in the period just before this last period, the VC understands that the last $x$ will only be spent if the 'good' state occurs. So the second to last $x$ is not invested either. Continuing this backward induction eventually brings us back to the first $x$.

This backward induction tells us that (in the absence of commitment) only an investor with an amount of capital $X=\frac{x}{r}$ can prevent the shock from impacting the firm NPV. ${ }^{14}$ This suggests that only very large firms with cash generating assets greater than $\mathrm{X}$ will not face financing risk. ${ }^{15}$ Empirically, this implies that the variation in innovation inside large firms who generate internal cash for $R \& D$ should be much more stable across time than aggregate innovation produced by startup firms. Furthermore, among venture capitalists, the largest funds that can potentially support a project to fruition without other future investors, are also less impacted by financing risk. This conveys a strong advantage to the largest funds that is most valuable and apparent in bad financing environments. Both of these predictions would be interesting to look for in the data.

In the absence of commitment, until an investor or a syndicate has more than $x / r$ (that can generate $x$ per period) more money will not prevent the firm from facing financing risk. This is because future unrelated investors are already acting rationally so unless the investors can commit to an irrational action in the future, they will act no differently from the market. However, we will see the importance of commitment in the next section.

\footnotetext{
${ }^{14}$ An investor with capital $X=\frac{x}{r}$ can invest forever. Thus, for this investor $V(0)=V(1)$ because they can always guarantee another round of funding. So their bargaining power would not be affected by the bad state. If $V(0)=V(1)$ then the conditions for financing risk to impact the firm in Proposition 1 cannot hold.

${ }^{15}$ For example, if a new venture needed $\$ 5 \mathrm{~m}$ each period and the discount rate, $r=10 \%$, then only an investor willing to dedicate $\$ 50 \mathrm{~m}$ to this investment would not be impacted by financing risk.
} 


\section{B. The Benefits and Costs of Commitment}

Increasing the dollars held by one investor or forming a syndicate does not protect the company from the shock because in each period the investment decision is made rationally and so a syndicate or even one investor with more money makes no decision differently than the market (until they have enough money that they never need the market again). After all, sunk costs are sunk. Therefore, if the market is rationally not investing, then any investor would make the same decision as the market.

However, we show that commitment to invest through a shock can change this result. We now allow an investor to commit to invest in the next period regardless of whether the shock has occurred.

Initially we will assume that contracts are complete and that there are no information asymmetries - so that the investor who has committed to invest in the second period does not invest if the project turns unviable (probability $\gamma_{l}$ ), but will invest if the project is viable and the shock has occurred. Alternatively, an equivalent contract is a state contingent contract where investors give a project $2 x$ or more in a period and the project commits to return any unused funds if the project becomes unviable but not if shock occurs.

Commitment trades off the potential increase in firm value with the potential loss from having to invest when $s(t)=0$. If an investor only invests a single $x$ then we know from above that the expected project NPV is equation (2). If instead an investor or syndicate commits to invest in both the first and the second period then we will refer to

the project NPV as $\left.\Pi_{t}\right|_{s(t)} ^{n=2}$ where the $n=2$ indicates two periods of commitment (one can think of all the NPVs above as having an implicit $n=1$, although from here forward we will explicitly indicate the number of periods of commitment). The extra period of commitment ensures that the project will receive an investment in the next period even if the shock has occurred, $s(t+1)=0$. This, in turn, alters the bargaining outcome of any sale, encourages buyers to purchase, etc so value of the firm increases. Therefore, the NPV when an investor commits to fund a project for two periods is

$$
\left.\Pi_{t}\right|_{s(t)} ^{n=2}=\frac{1-\gamma_{l}-\gamma_{a}}{1+r}\left[\left.Y \Pi_{t+1}\right|_{s(t+1)=0} ^{n=1}+\left.Z \Pi_{t+1}\right|_{s(t+1)=1} ^{n=1}\right]+\frac{\gamma_{a}}{1+r} V(1)-x
$$


where $Z=s(t) \theta+(1-s(t))(1-\phi)$ and $Y=s(t)(1-\theta)+(1-s(t)) \phi$. Appendix A.A4 solves for the profits for any level of commitment $n=N$.

This equation differs from equation (2) in two ways. First, the value if exit occurs is high, $V(1)$, even if the state transitions to $s(t+1)=0$ because funding is certain. Second, the investor has agreed to provide financing if $s(t+1)=0$. Therefore, if $s(t+1)=0$, the investor makes an expected loss since $\left.\Pi_{t+1}\right|_{s(t+1)=0} ^{n=1}<0$.

Thus, the question of whether it is better to commit to a second round of investment is a question of whether profits with commitment are bigger than profits without. Subtracting the two profit equations, the question is reduced to whether $\left.\Pi_{t}\right|_{s(t)} ^{n=2}-\left.\Pi_{t}\right|_{s(t)} ^{n=1}>0$ or

$$
\left.\Pi_{t}\right|_{s(t)} ^{n=2}-\left.\Pi_{t}\right|_{s(t)} ^{n=1}=\left.\frac{1-\gamma_{l}-\gamma_{a}}{1+r} Y \Pi_{t+1}\right|_{s(t+1)=0} ^{n=1}+\frac{\gamma_{a}}{1+r} Y[V(1)-V(0)]>0 ?
$$

where $Y=s(t)(1-\theta)+(1-s(t)) \phi$. Thus, we can see that the question becomes one of whether or not the expected improvement in firm value if an acquirer is found, $[V(1)-$ $V(0)$ ], is worth the potential negative expected value investment if the signal $s(t+1)=0$ and there is no acquisition (because $\left.\Pi_{t+1}\right|_{s(t+1)=0} ^{n=1}<0$ ).

The following proposition shows the impact of this trade-off.

PROPOSITION 2: Let $F$ represent the subset of projects with parameters such that the conditions in Proposition 1 are met for the funding to depend on the signal. If investors or syndicates can commit to invest in future periods and contracts are complete, then for any project in $F$ any increase the the capital committed, $n$, increases the project NPV and a large enough capital commitment, $n>\bar{N}$, makes the funding equilibrium no longer depend on the signal, i.e. the project is no longer impacted by financing risk.

\section{PROOF:}

See Appendix A.A4

By committing to a third period of investment the investor essentially 'puts off' potentially having to make the negative NPV investment by one period. Simultaneously committing more improves the projects value (by improving its bargaining power) for all periods of commitment. Thus, eventually by committing to fund the project for enough periods the bargaining improvement outweighs the ever more unlikely negative NPV investment. The negative NPV investment becomes less and less likely because a 
firm with more money is more likely to be acquired or fail before it runs out of money and it is only when the project has little money that it becomes negative NPV.

Therefore, large investors and syndicates can actually increase the NPV of the projects they fund by giving them more dollars or implicitly or explicitly committing to fund them for longer. Enough committed dollars make the project NPV positive even if financing risk is high. For these projects commitment eliminates the impact financing risk.

The logic above would seem to suggest that all projects should get significant upfront funding. However, as noted above, we have so far assumed that an investor or syndicate that commits to fund a project can withdraw funding if the project becomes unviable, i.e. the commitment only relates to the state of the world and not to the project quality.

The analogous venture capital contract is a tranched investment, in which the investors have committed to fund a project if certain milestones are reached. These type of contracts provide the investor with a real option, but we believe they are also an attempt to overcome financing risk as they commit the investor to invest if the company has done well even if the world has done poorly. However, they rarely cover more than one future financing, and for many projects (particularly innovative ones), it is very difficult to articulate and delineate a clear milestone. Thus, it is unrealistic to assume that complete state-contingent contracts can be written for all future funding dates at the start of a project. The next section explores the trade-offs under the more realistic scenario of incomplete contracts.

\section{Incomplete Contracts and the Lost Real Option}

This section explains why this paper is ultimately about experimenting/innovative/high real option firms. In a realistic setting with incomplete contracts across time we will see a fundamental tradeoff in the amount of money provided to innovative firms that leaves them impacted by financing risk in equilibrium.

Complete contracts are unrealistic as investors cannot contract on every future funding need at the start of a project. In this section, we assume that contracts are incomplete. This is similar to Grossman and Hart (1986) and Hart and Moore (1990), however, while they require non-contractibility of prices we only assume a more limited non-verifiability of states. We assume that it is not possible to either write down or verify all future states in which funding should or should not occur. For example, it might be the case that 
states of nature are observable by the investors but not verifiable by a court. Specifically we define an incomplete contract as follows.

DEFINITION 1: In an incomplete contract, investors cannot contract on actions that differ between a shock, $s(t+1)=0$, and a project becoming unviable, (which happens with probability $\gamma_{l}$ ).

We continue to assume commitment is enforceable, as in the last section, but now, without complete contracts, investors are not able to write contracts that release them (or return unused capital) when bad firm specific information arrives. We further add the assumption that entrepreneurs have a private benefit of control and thus benefit from continuing the firm. ${ }^{16}$ Therefore, without a contract that requires the entrepreneur to shut down given bad information the project will continue until it is out of money. This is essentially the assumption that an entrepreneur with more money will spend more and at least some of it in a wasteful manner. ${ }^{17}$

If the money given to a firm will be spent, then giving more money to a firm destroys some of the value of the firm's real option to shut down in the event that intermediate information is not positive. On the other hand, more money better protects the firm from the negative shock.

In our model the real option value in a firm depends on the probability that a firm loses viability before it is sold. If $\gamma_{l}=0$ the firm is always viable and there is no real option value in shutting the firm down (as it never needs to be shut down). However, for higher values of $\gamma_{l}$ it becomes valuable to give the firm less up front funding (smaller commitment) and wait to learn that it is still a viable firm in the next period. So holding the NPV of a firm constant, a firm with a greater $\gamma_{l}$ has more option value, i.e., it is more valuable to be able to abandon the project.

Thus, a firm with greater $\gamma_{l}$ is more 'experimental' in that it is more valuable to run this firm by trying things and waiting to see the outcome. We argue that more innovative projects require a greater need to test or experiment before proceeding, as well as more early stage firms. Thus, another way to state this proposition is that we are demonstrating

\footnotetext{
${ }^{16}$ It is not hard to believe that since it is not their money, entrepreneurs/employees might like to continue past when investors would like to shut down.

${ }^{17}$ The main tradeoff is the same if only a fraction of the committed money would be spent after the arrival of bad news.
} 
the effect of financing risk on investors' willingness to finance innovative firms.

We can see the effect of incomplete contracts and real options on the profitability of committing extra dollars to a firm. In section II, when we assumed complete contracts, the profit from committing to invest an extra $x$ was equation (6). With complete contracts, the investor would not lose the second committed $x$ if the project lost viability. Now, however, committing $2 x$ requires the investor to lose the second $x$ if the project fails (i.e., it will be spent by the entrepreneur). Thus, the expected profit from committing $2 x$ becomes

$$
\left.\Pi_{t}\right|_{s(t)} ^{n=2}=\frac{1-\gamma_{l}-\gamma_{a}}{1+r}\left[\left.Y \Pi_{t+1}\right|_{s(t+1)=0} ^{n=1}+\left.Z \Pi_{t+1}\right|_{s(t+1)=1} ^{n=1}\right]+\frac{\gamma_{a}}{1+r} V(1)-x\left(1+\frac{\gamma_{l}}{1+r}\right)
$$

where $Z=s(t) \theta+(1-s(t))(1-\phi)$ and $Y=s(t)(1-\theta)+(1-s(t)) \phi$.

The difference between the profit function with complete contracts equation (6) and without is the option value of potentially abandoning the project after one period instead of funding it for two. This equals $\frac{\gamma_{l}}{1+r} x$. Another way to say this is that it is the additional cost to commitment when the money will be spent even if the firm fails. This leads directly to our next proposition

PROPOSITION 3: Incomplete contracts reduce the value of committing more money and the reduction in value is larger for firms with larger $\gamma_{l}$ and $x$, i.e., more experimental firms with more costly experiments who have more real option value. Furthermore, for firms with large enough $x$ and $\gamma_{l}$ increasing commitment can change it from a positive to a negative NPV project.

\section{PROOF:}

See Appendix A.A5

The central insight comes from comparing the profit equations with and without complete contracts. Note that if $\gamma_{l}=0$ there is no real option value and no difference between the profit functions. ${ }^{18}$ However, with incomplete contracts, holding the NPV constant, the larger $\gamma_{l}$ becomes the more valuable it becomes to give the project only one period of funding to see if it fails. This is exacerbated the larger the required investment

\footnotetext{
${ }^{18}$ With $\gamma_{l}=0$ there is no chance the project will fail so commitment only effects the No-Invest state of the world. Thus, when $\gamma_{l}=0$ then just like in the last section, commitment trades off the cost of investing during the No-Invest equilibrium with the potential increase is sale price from doing so. But committing enough money always eliminates the No-Invest equilibrium.
} 
x. Thus, commitment becomes more and more costly. Investors who give a firm enough funding to fully protect it from the shock lose the option to give the firm a little funding and wait to see how it performs to give it more. Therefore, it is more costly to protect innovative projects with high real option value from the shock. Less innovative firms can be given a larger amount of upfront financing in order to prevent the shock from affecting them. But the most innovative firms cannot be given significant funding up front or the loss of the real options may change it to an NPV negative project. Therefore, more innovative firms should receive less funding up front and are more exposed to financing risk.

For example, compare the funding of a coal power plant to a novel bio-fuel power plant. The established coal technology needs no experimentation and can be built at scale. The financing for a project like this can be committed at the start and so it is unaffected by future financial market conditions. However, a new bio-fuel refinery where the yields are unproven requires pilot tests and demonstration plants before being adopted at scale. In a perfect world, complete contracts could allow investors to commit to fund the full-scale project at the early stages of innovation. However, to the extent that this is not possible the project will be forced to raise funding at each stage - exposing it to market shocks. Investors may try to form a large syndicate or provide more substantial upfront funding, but they will find it NPV negative to commit to fund the entire project ex-ante. Thus, the more a project has a wait-and-learn-more aspect to it the more it will face a trade-off between maximizing real option value and defending against financing risk.

We specifically model the option to abandon the project. However, our ideas and results relate to all types of real options, like an expansion option, where it is optimal to wait to provide more money. Any delay in fully funding all the potential project needs exposes the firm to financing risk and creates a trade-off between protecting against financing risk and maximizing real option value.

Thus, in a world with incomplete contracts, less innovative firms are not hurt as much by the prospect of financing risk. Instead it is the innovative end of the economy that is most impacted by waves of investor interest and disinterest in the sector. This does not require any behavioral explanation, although the effect could certainly be magnified by behavioral considerations. Rational investors know they face financing risk. They 
rationally try to mitigate that risk by forming syndicates and providing larger sums of money up-front. But for more innovative firms providing more money reduces the option value of the investment. Thus, innovative projects must be left exposed to the whims of the financial market.

\section{Implications}

\section{A. Innovation, Project Mix and Financing Risk}

A key implication of our model is that we should see high and low levels of innovative activity that are driven by shocks in the capital markets.

Investors attempt to protect their firm from the effect of a financial market shock by committing more money to a firm up front, but the more innovative the firm the more likely early failure may occur and the more costly it is to commit significant money up front.

Any increase in financing risk ${ }^{19}$ lowers the NPV of all firms that that are impacted by financing risk. If this occurs some firms will become NPV negative with their current level of commitment. At which point some of these firms will be unable to get funding while other firms may find it value enhancing to raise more money and thereby reduce the value of some of their real options but defend better against the potential shock.

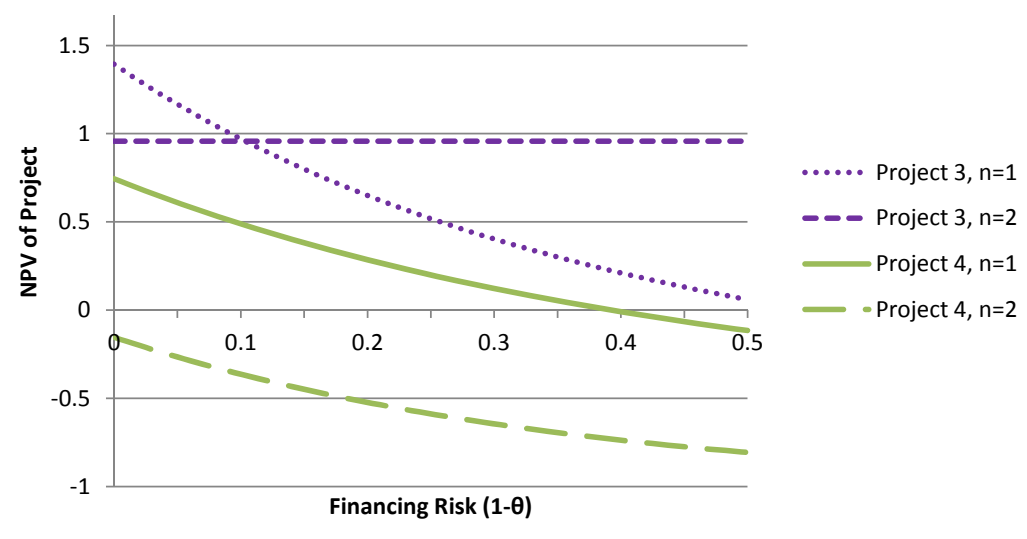

Figure 5. Financing Risk and InCREased Funding

Consider projects 3 and 4 in figure 5 . The only difference between them is that project 3 has a lower probability of failure. With no financing risk both projects have a higher

${ }^{19} \mathrm{~A}$ decrease in $\theta$ or an increase in $\phi$. 
NPV if they raise only one unit of financing (on the left side of the graph the lines with $n=1$ are higher than the corresponding $n=2$ lines). However, as financing risk increases eventually Project 3 creates more value by raising two units of capital, but project 4 is always worth less if it raises an extra unit of capital. This is because it is more costly for project 4 to raise an extra $x$ because it is more likely to fail, i.e., it is more valuable to take a wait-and-see approach even though this leaves the project exposed to more financing risk. Eventually, if financing risk gets high enough, project 4 will not raise even one $x$ because it becomes NPV negative.

The most innovative sectors or places, will have firms where interim failure is high and a wait-and-see approach is important. These firms will be unable to raise significant up-front financing because too much value is destroyed in the loss of their real options. So in times when financing risk is low, more firms will be financed and the mix of financed firms should become more innovative.

Aggregating this effect up across all firms we would expect times of increased innovation to come from times of increased experimentation by investors. Thus, lower financing risk should lead to a more innovative group of new ventures being funded and therefore, to more innovation. In fact, using data on patent filings for venture capital backed firms, Nanda and Rhodes-Kropf (2013) find evidence that is consistent with this view. In a related test Li (2011) reports that financial constraints only negatively impact R\&D intensive firms. Our work suggest that this is because only experimental firms cannot be fully protected from the impact of financing risk.

Relatedly, direct measures of innovation such as patenting occur in great waves of activity (see Griliches, 1990). There are many explanations for why innovative output might cluster in certain periods of time even though we expect ideas to occur at random. The classical explanations focus on sudden breakthroughs that lead to a cascade of follow-on inventions (e.g. Schumpeter, 1939; Kuznets, 1940; Kleinknecht, 1987; Stein, 1997) or on changes in sales and profitability (or potential profitability) that stimulate investment in $\mathrm{R} \& \mathrm{D}$ and then drive concentrated periods of innovation (e.g. Schmookler $(1966)) .{ }^{20}$ While these traditional explanations clearly have merit, combining our model of financing risk with the direct evidence on the link between financial market activity and

\footnotetext{
${ }^{20}$ See Stoneman (1979) for a discussion of the supply versus demand considerations.
} 
innovation (Kortum and Lerner (2000), Mollica and Zingales (2007), Samila and Sorenson (2011)) suggests that financial markets may play a much larger and under-studied role in the creation and magnification of innovation waves in the real economy. Financial market activity may drive concentration in the commercialization of innovation, even if the inventions occurred at random.

\section{B. Funding Levels and Financing Risk}

We can see from figure 5 that as financing risk increases, some firms may be unable to get financing but others will actually raise more money. This results in a surprising prediction that matches anecdotal evidence: when financing risk is high, many experimental firms can no longer get financing but the few that do get funding actually get more funding. When venture capital investing dried up in 2009, anecdotal evidence suggests that investors told some firms that they would only invest if the firm took an extra large amount of money relative to their annual capital need to make sure they would not have to come back to the financial markets for an extended period. Thus, while many firms were finding it impossible to raise money others were being asked to take enough for multiple years.

So our empirical prediction is that less total money will enter a sector during 'bad' times, and fewer firms will get funded, the few firms that get funded will be well funded relative to their annual spending. ${ }^{21}$

\section{Firm Stage and Financing Risk}

The above model can be redone with multiple hurdles or stages. For example a project might have to first prove it works (hurdle A) and then prove it can be mass produced in a low cost fashion (hurdle B). Firms at different stages might need different amounts of funding, $x^{A}$ and $x^{B}$, and have different probabilities of acquisition and failure, $\gamma_{a}^{A}, \gamma_{l}^{A}, \gamma_{a}^{B}$ and $\gamma_{l}^{B}$, where success at stage A means the ability to attempt stage B. ${ }^{22}$

It is likely that for most projects the earlier the stage of the project the more likely it is to fail (i.e. $\gamma_{l}^{A}>\gamma_{l}^{B}$ ). Since Proposition 3 demonstrates that the value of committing more capital is lower for firms with larger probabilities of failure, it is the early stage firms,

\footnotetext{
${ }^{21}$ Note we are not suggesting that firms will get more funding in bad times, only that those that get funded should have more funding relative to their expenses so they can better survive the funding drought.

${ }^{22}$ This model has also been solved by the authors and all above propositions hold and is available upon request.
} 
on average, that are less able to defend against financing risk and are more impacted by it. Therefore, early stage firms should get less funding (relative to burn rate) than later stage firms and should have to go back for financing sooner. Furthermore, as financing risk changes through time we should see a larger fluctuation in the birth of early stage firms and funding for early stage firms relative to later stage projects.

We can imagine projects with more than two stages. Projects with stages A, B, C, D, etc, face more financing risk than a project with only one stage (holding other parameters constant) and has more chances to fail. Essentially projects with only one stage can be more certain they have the money they need when they start relative to a project with many hurdles to jump. This suggests that projects that require more money spent over longer time frames face greater financing risk.

\section{Investor Mix and Financing Risk}

Lower financing risk lowers the amount of capital firms need and should therefore also allow smaller investors with more limited capital to invest. Our model therefore suggests that in good times the mix of investors should shift towards investors with less capital. In bad times, a large investor might be able to give a firm more support and protect them from the financing shock but small investors don't have this option and must therefore stop investing (Janeway, 2012). In the low investing times small, so-called angel, investors should significantly reducing investing relative to larger investors, assuming, of course, that the coordination costs to bring together enough small investors is too high. So larger investors should more consistently invest across time.

\section{E. 'Herd Behavior' in Innovative Investments}

Conventional wisdom (and most past work) suggests that contrarian strategies might be good because a flood of money lowers the discipline of external finance and allows lower quality projects to get capital (Gompers and Lerner, 2000; Nanda, 2008). Our model implies that this is not true in every case. In our model, fully rational investors who only make NPV positive investments are optimally entering the market when prices are high (because the financing risk is low) and there is increased investing activity. When financing risk is low, it is optimal to give a firm less money and see how it does. Smaller investors who 
face greater hurdles to forming large pools of money can find valuable investments in high real option companies that need only a little money but only during good times. Making this same investment when the probability of future funding is low is NPV negative. Thus for innovative projects with high real option value, it may actually make sense to invest with the crowd.

The corollary to this view also provides a more positive interpretation to the increase in capital that is associated with the initial diffusion of very radical new technologies, such as railways, motor cars, internet or clean energy technologies. Our model implies that such technologies may in fact need 'hot' financial markets, where financing risk is extremely low and many investors are in the market, to help with the initial diffusion of such technologies.

\section{Conclusion}

Startups have been associated with the initial diffusion of several technological revolutions (railway, semiconductors and computers, internet, motor cars, clean technology) and there is increasing evidence of the important role of startup firms in driving aggregate productivity growth in the economy (Foster, Haltiwanger and Syverson (2008)). This paper builds on the emerging research examining the role of the capital markets in driving innovation in the real economy (Kortum and Lerner (2000), Mollica and Zingales (2007), Samila and Sorenson (2011)) and provides a mechanism for why investors may increase experimentation during some periods. We depart from the view that financial market activity is purely a response to novel technologies and suggest instead that financial markets drive innovative activity.

We argue that a particular feature of innovative startups is that they don't know how much investment will be required to get to the 'finish line'. Intermediate results may be equivocal, or additional investments may be required to get to cash flow positive. Any investor in such startups with limited resources must therefore also rely on other investors to bring innovative firms to fruition.

Because of this, such startups face two risks - fundamental risk (that the project gets an investment but turns out not to be viable) and financing risk (that the project needs more money to proceed but cannot get the financing even if it is fundamentally 
sound). Financing risk is typically ignored in the literature because all firms with positive fundamental NPV are assumed to get funded. This ignores the fact that investing requires coordination across time between investors with limited resources. Investors must, therefore, forecast the probability that other investors will be there to fund the firm in the future. A low forecast in the probability of future funding reduces the NPV of the project and makes the decision not to invest rational. Thus, financing risk is part of a rational equilibrium.

The impact of financing risk on a firm can be reduced by giving the firm more funding. However, this comes at a cost. A firm with more funding may spend some or all of the money even in the event of disappointing intermediate information. This cost is greater for highly experimental firms where the real option to shut down the firm is most valuable. The more valuable the real option to shut down a firm, the less funding the firm should receive at a given time. Firms that receive less funding are more affected by a financing shock. Thus, early round investors investing in innovative firms face an important trade-off between lowering financing risk and increasing real option value. The most innovative firms are thus most susceptible to financing risk as they are least able to acquire a 'war chest' to survive a down turn.

We show that financing risk is inherent to the funding of innovative new ventures and demonstrate its impact. We argue that the most innovative firms, or those in the early period of a technology adoption, may need 'hot' financing environments to help with their initial financing or diffusion. This implies that a fundamentally different, more innovative type of project will be funded in 'hot' rather than 'cold' markets. By driving experimentation, financing risk may play a key role in creating and magnifying technological revolutions and the process of creative destruction. 


\section{REFERENCES}

Acharya, Viral, Douglas Gale, and Tanju Yorulmazer. 2011. "Rollover risk and market freezes." Journal of Finance, 66: 11771209.

Aghion, Philippe, and Peter Howitt. 1992. "A Model of Growth through Creative Destruction." Econometrica, 60: 323-351.

Bergemann, Dirk, and Ulrich Hege. 2005. "The Financing of Innovation: Learning and Stopping." RAND Journal of Economics, 36: 719-752.

Bergemann, Dirk, Ulrich Hege, and Liang Peng. 2008. "Venture Capital and Sequential Investments." Yale University working paper.

Black, Bernard S, and Ronald J Gilson. 1998. "Venture capital and the structure of capital markets:banks versus stock markets." Journal of Financial Economics, 47(3): $243-277$.

Bloom, Nick. 2009. "The Impact of Uncertianty Shocks." Econometrica, 77: 623-685.

Carlsson, Hans, and Eric van Damme. 1993. "Global Games and Equilibrium Selection." Econometrica, 61(5): 989-1018.

Chatterjee, Satyajit, Russell Cooper, and B. Ravikumar. 1993. "Strategic Complementarity in Business Formation: Aggregate Fluctuations and Sunspot Equilibria." The Review of Economic Studies, 60(4): 795-811.

Cooper, Russell W., and Andrew John. 1988. "Coordinating Coordination Failures in Keynesian Models." Quarterly Journal of Economics, 103: 441-464.

Diamond, Peter A. 1982. "Aggregate Demand Management in Search Equilibrium." Journal of Political Economy, 90(5): 881-894.

Fagnan, David E., Jose-Maria Fernandez, Andrew W. Lo, and Roger M. Stein. 2013. "Can Financial Engineering Cure Cancer?" American Economic Review: Papers and Proccedings, 103(3): 406-411. 
Fernandez, Jose-Maria, Roger M. Stein, and Andrew W. Lo. 2012. "Commercializing Biomedical Research Through Securitization Techniques." Nature Biotechnology, 30: 395-400.

Foster, Lucia, John Haltiwanger, and Chad Syverson. 2008. "Reallocation, Firm Turnover and Efficiency: Selection on Productivity or Profitability." The American Economic Review, 98(1): 394-425.

Goldstein, Itay, and Ady Pauzner. 2004. "Contagion of self-fulfilling financial crises due to diversification of investment portfolios." Journal of Economic Theory, 119: $151-183$.

Gompers, Paul. 1995. "Optimal Investment, Monitoring, and the Staging of Venture Capital." Journal of Finance, 50: 1461-1489.

Gompers, Paul, and Josh Lerner. 1998. "Venture capital distributions: short-run and long-run reactions." Journal of Finance, 53: 2161-2183.

Gompers, Paul, and Josh Lerner. 2000. "Money chasing deals? The impact of fund inflows on private equity valuations." Journal of Financial Economics, 55: 281-325.

Gompers, Paul, and Josh Lerner. 2004. The Venture Capital Cycle. Cambridge, MA: MIT Press.

Gompers, Paul, Anna Kovner, Josh Lerner, and David Scharfstein. 2008. "Venture capital investment cycles: The impact of public markets." Journal of Financial Economics, 87: 1-23.

Griliches, Zvi. 1990. "Patent Statistics as Economic Indicators: A Survey." Journal of Economic Literature, 28(4): 1661-1707.

Grossman, Sanford J., and Oliver D. Hart. 1986. "The costs and benefits of ownership: A theory of vertical and lateral integration." Journal of Political Economy, 94: 691-719.

Hart, Oliver D., and John Moore. 1990. "Property rights and the nature of the firm." Journal of Political Economy, 98: 1119-1158. 
Hellmann, Thomas. 2002. "A Theory of Strategic Venture Investing." Journal of Financial Economics, 64(2): 285-314.

Hellmann, Thomas, and Manju Puri. 2000. "The Interaction between Product Market and Financing Strategy: The Role of Venture Capital." Review of Financial Studies, 13(4): 959-984.

Hellmann, Thomas, and Manju Puri. 2002. "Venture Capital and the Professionalization of Start-Up Firms: Empirical Evidence." Journal of Finance, 57(1): 169-197.

He, Zhiguo, and Wei Xiong. 2012a. "Dynamic debt runs." Review of Financial Studies, 25(6): 1799-1843.

He, Zhiguo, and Wei Xiong. 2012b. "Rollover Risk and Credit Risk." Journal of Finance, 67(2): 391-429.

Hobijn, Bart, and Boyan Jovanovic. 2001. "The Information-Technology Revolution and the Stock Market: Evidence." The American Economic Review, 91(5): 1203-1220.

Hsu, David. 2004. "What Do Entrepreneurs Pay for Venture Capital Affiliation?" Journal of Finance, 59: 1805-1844.

Janeway, William H. 2012. Doing Capitalism in the Innovation Economy. Cambridge, UK: Cambridge University Press.

Kaplan, Steven, and Antoinette Schoar. 2005. "Private Equity Performance: Returns, Persistence and Capital Flows." Journal of Finance, 60(4): 1791-1823.

Kaplan, Steven, Berk Sensoy, and Per Stromberg. 2009. "Should Investors Bet on the Jockey or the Horse? Evidence from the Evolution of Firms from Early Business Plans to Public Companies." Journal of Finance, 64(1).

Kerr, William R., and Ramana Nanda. 2009. "Democratizing Entry: Banking Deregulations, Financing Constraints, and Entrepreneurship." Journal of Financial Economics, 94(1): 124-149.

Kindleberger, Charles. 1978. Manias, Panics, and Crashes: A History of Financial Crises. . revised and enlarged, 1989, 3rd ed 1996 ed., New York: Basic Books. 
Kleinknecht, Arthur. 1987. Innovation Patterns in Crisis and Prosperity. McMillan.

Klepper, Steven, and Elizabeth Graddy. 1990. "The Evolution of New Industries and the Determinants of Market Structure." Rand Journal of Economics, 21(1): 27-44.

Kortum, Samuel, and Josh Lerner. 2000. "Assessing the impact of venture capital on innovation." Rand Journal of Economics, 31: 674-92.

Kuznets, Simon. 1940. "Schumpeter's Business Cycles." American Economic Review, $30(2): 257-271$.

Lamoreaux, Naomi R., and Kenneth L. Sokoloff. 2007. Financing Invention in the United States, 1870 to the present. Cambridge, MA:MIT Press.

Lerner, Josh, Morten Sorensen, and Per Stromberg. 2011. "Private Equity and Long-Run Investment: The Case of Innovation." Journal of Finance, 66(2): 445-477.

Li, Dongmei. 2011. "Financial Constraints, R\&D Investment, and Stock Returns." Review of Financial Studies, 24(9): 2974-3007.

Manso, Gustavo. 2011. "Motivating Innovation.” Journal of Finance, 66(5): 1823-1860.

Matsuyama, Kiminori. 1995. "Association Complementarities and Cumulative Processes in Models of Monopolistic Competition." Journal of Economic Literature, $33(2): 701-729$.

Mollica, Marcos, and Luigi Zingales. 2007. "The impact of venture capital on innovation and the creation of new businesses." University of Chicago working paper.

Morris, Stephen, and Hyun Song Shin. 1998. "Unique Equilibrium in a Model of Self-Fulfilling Currency Attacks." American Economic Review, 88(3): 587-597.

Murphy, Kevin M., Andrei Shleifer, and Robert W. Vishny. 1989. "Industrialization and the big push." Journal of Political Economy, 97(5): 1003-1026.

Nanda, Ramana. 2008. "Entrepreneurship and the Discipline of External Finance." Harvard University Working Paper.

Nanda, Ramana, and Matthew Rhodes-Kropf. 2013. "Investment Cycles and Startup Innovation." Journal of Financial Economics, Forthcoming. 
Pastor, Lubos, and Pietro Veronesi. 2009. "Technological Revolutions and Stock Prices." American Economic Review, 99: 1451-1483.

Perez, Carlota. 2002. Technological Revolutions and Financial Capital. Edward Elgar.

Rhodes-Kropf, Matthew, and David Robinson. 2008. "Mergers and the Boundaries of the Firm." Journal of Finance, LXIII(8): 1169-1211.

Samila, Sampsa, and Olav Sorenson. 2011. "Venture capital, entrepreneurship and economic growth." Review of Economics and Statistics, 93: 338-349.

Scharfstein, David, and Jeremy Stein. 1990. "Herd behavior and investment." American Economic Review, 80: 465-479.

Schmookler, Jacob. 1966. Invention and Economic Growth. Harvard University Press.

Schumpeter, Joseph. 1939. Business Cycles: A Theoretical, Historical and Statistical Analysis of the Capitalist Process. McGraw Hill.

Schumpeter, Joseph. 1942. Capitalism, Socialism and Democracy. New York: Harper.

Shleifer, Andrei. 1986. "Implementation Cycles." Journal of Political Economy, 94(6): 1163-1190.

Sorensen, Morton. 2007. "How smart is smart money? An empirical two-sided matching model of venture capital." Journal of Finance, 62: 2725-62.

Stein, Jeremy C. 1997. "Waves of creative destruction: Firm-specific learning-by-doing and the dynamics of innovation." The Review of Economic Studies, 64(2): 265-288.

Stoneman, P. 1979. "Patenting Activity: A Re-evaluation of the Influence of Demand Pressures." Journal of Industrial Economics, 27(4): 385-401.

Tian, Xuan, and Tracy Yue Wang. 2011. "Tolerance for Failure and Corporate Innovation." Review of Financial Studies, Forthcoming. 


\section{Mathematical Appendix}

\section{A1. Bargaining Model of $V(1)>V(0)$}

In this section of the appendix we model the acquisition negotiations. With probability $\gamma_{a}$ a potential strategic acquirer arrives who values the firm at $\widehat{\Pi}$ (the $\widehat{h a t}$ will signify the acquirer throughout the appendix). ${ }^{23}$ The potential acquirer and target negotiate the price for the transaction. The negotiation, if consummated, results in the target receiving a price $V(s(t+1))(t+1$ denotes the fact that the negotiation takes place one period after the initial investment at time $t$ ). To determine the sale price we use the Nash bargaining solution, so the transaction price will depend on the potential acquirer's value and the opportunity cost if either side walks away from the deal.

Acquisition negotiations under the Nash bargaining solution depend on the potential acquirer's value and the outside opportunities of each party. If the target walks away from the negotiation, the target is worth the NPV from continuing to look for investors and an acquirer, $\left.\Pi_{t+1}\right|_{s(t+1)}$. Under the assumption that $\max \left[\left.\Pi_{t+1}\right|_{s(t+1)=0}, 0\right]=0$ (the project will not be financed if the signal is zero), the target's outside option or reservation value can be written as $\left.s(t+1) \Pi_{t+1}\right|_{s(t+1)=1}$ because if $s(t+1)=0$ then the target's outside option becomes zero. If the potential acquirer does not purchase the target then they earn nothing. If, however, the firm is sold to a different acquirer when not purchased by this potential acquirer then the potential acquirer's value is reduced by $\lambda \widehat{\Pi}$. Since this loss only occurs if the project is sold to someone else, the expected loss depends on the company receiving enough financing to stay alive to be sold to someone else in the future. Therefore, the expected cost to the potential acquirer if he does not purchase the target is

$$
\left.\widehat{C}_{t}\right|_{s(t)}=\frac{1-\gamma_{l}-\gamma_{a}}{1+r}\left[\left.Z \widehat{C}_{t+1}\right|_{s(t+1)=1}+\left.Y \widehat{C}_{t+1}\right|_{s(t+1)=0}\right]+\frac{\gamma_{a}}{1+r} \lambda \widehat{\Pi}
$$

And under the belief that the target will not get financing next period if $s(t+1)=0$ this

\footnotetext{
${ }^{23}$ One might think the probability of arrival is less than one because it is costly and time consuming for potential acquires to find and determine their value for a target (particularly small private targets), so potential acquires only arrive in a given period with probability $\gamma_{a}$. The idea that acquires and target's must search for one another is fully developed in Rhodes-Kropf and Robinson (2008).
} 
expected cost becomes

$$
\left.\widehat{C}_{t}\right|_{s(t)}=\left.\frac{1-\gamma_{l}-\gamma_{a}}{1+r} Z \widehat{C}_{t+1}\right|_{s(t+1)=1}+\frac{\gamma_{a}}{1+r} \lambda \widehat{\Pi}
$$

Therefore, exploiting the same stationarity in the model, the potential acquirer expects to lose

$$
\left.\widehat{C}\right|_{s(t)=1}=-\frac{\gamma_{a} \lambda \widehat{\Pi}}{(1+r)-Z\left(1-\gamma_{l}-\gamma_{a}\right)}
$$

or $\left.\widehat{C}\right|_{s(t)=0}=0$. These assumptions allow functional forms for $V(0)$ and $V(1)$.

The set of possible acquisition agreements, $\widehat{V}(s(t+1))$ for the acquirer and $V(s(t+1))$ for the target is

$$
\begin{array}{r}
v=\left\{\left(\widehat{V}(s(t+1)), V(s(t+1)):\left.s(t+1) \Pi_{t+1}\right|_{s(t+1)} \leq V(s(t+1)) \leq \widehat{\Pi}-\left.s(t+1) \widehat{C}\right|_{s(t+1)=1}\right.\right. \\
\text { and } \left.\widehat{V}(s(t+1))=\widehat{\Pi}-\left.s(t+1) \widehat{C}\right|_{s(t+1)=1}-V(s(t+1))\right\} \quad(\mathrm{A} 4)
\end{array}
$$

where $s(t+1) \in[0,1] .{ }^{24}$ Note that the acquirer's expected loss, $\left.\widehat{C}\right|_{s(t+1)=1}$ if next period's signal is 1 , is multiplied by $s(t+1)$. This is because the potential acquirer only expects losses if the firm continues when it is not bought which can happen only if the firm gets funded.

Using the well known Nash bargaining solution, the equilibrium split is just ${ }^{25}$

$$
V(s(t+1))=\frac{1}{2}\left(\widehat{\Pi}-\left.s(t+1) \widehat{C}\right|_{s(t+1)=1}+\left.s(t+1) \Pi_{t+1}\right|_{s(t+1)=1}\right)
$$

where $\left.\widehat{C}\right|_{s(t+1)=1}$ is defined by equation (A3), and $\left.\Pi_{t+1}\right|_{s(t+1)=1}$ is defined by equation (3). Substituting in using equation (A3) and (3) we find

$$
V(s(t+1))=\frac{1}{2}\left(\widehat{\Pi}+s(t+1) \frac{\gamma_{a} \lambda \widehat{\Pi}}{(1+r)-\theta\left(1-\gamma_{l}-\gamma_{a}\right)}\right.
$$

\footnotetext{
${ }^{24}$ Note that since the potential acquire expects to lose some value if they face the target as a competitor, they are willing (but may not have to) pay more than $\widehat{\Pi}$ to acquire the target to prevent the loss i.e. $\widehat{C}$ is a negative number.

${ }^{25}$ More generally one might expect that if the firm could not find future funding its bargaining position might be affect in ways other than just through the reservation values. In the generalized Nash bargaining solution, for example, one might think the bargaining power exponent parameters also shifted to favor the acquirer. This effect would magnify the results presented here.
} 


$$
\left.+s(t+1) \frac{\gamma_{a}[\theta V(1)+(1-\theta) V(0)]-x(1+r)}{(1+r)-\theta\left(1-\gamma_{l}-\gamma_{a}\right)}\right)
$$

Therefore, $V(0)=\widehat{\Pi} / 2$. And we can solve for $V(1)$.

$$
V(1)=\frac{1}{2}\left(\widehat{\Pi}+\frac{\gamma_{a} \lambda \widehat{\Pi}}{(1+r)-\theta\left(1-\gamma_{l}-\gamma_{a}\right)}+\frac{\gamma_{a}[\theta V(1)+(1-\theta) \widehat{\Pi} / 2]-x(1+r)}{(1+r)-\theta\left(1-\gamma_{l}-\gamma_{a}\right)}\right)
$$

Reduces to

$$
V(1)=\widehat{\Pi} / 2+\frac{\widehat{\Pi}\left(\gamma_{a} \lambda+\gamma_{a} / 2\right)-x(1+r)}{2(1+r)-2 \theta\left(1-\gamma_{l}-\gamma_{a} / 2\right)}
$$

And we can see that $V(1)>V(0)$ as long as $\widehat{\Pi}\left(\gamma_{a} \lambda+\gamma_{a} / 2\right)>x(1+r)$ and the project will not get funding if $s(t+1)=0$. However, if the project will get funded even if $s(t+1)=0$ then $V(1)=V(0)$ and both are defined by equation (A8).

\section{A2. Proof that a simpler model wont have financing risk:}

Some readers may feel that financing risk could be generated with a simpler model after all, ignoring any effects from sale negotiations, couldn't a project turn NPV negative if early investors forecast no future investors will support it? Yes, however, such a belief would be irrational and in the future investors would rationally support it. Thus, this kind of model would NOT have rational equilibrium financing risk. Although our implications and results do hold in a world with irrational financing risk, our model helps demonstrate that no irrationality is needed, which has important implications.

To demonstrate that a simpler model would not work consider the following model.

A project with NPV $\Pi$ pays off $V$ with probability $p$ and with a probability $(1-p)$ it needs another $x$. Investing $x$ buys the investor a fraction $q$. A rational investor will invest as long as the fraction $q \geq \frac{x}{\Pi+x}$.

If investors forecast a No-Invest state then they will invest as long as $x \leq q p V$. This is because the present value of the project is $p V$ so they invest if their fraction $q$ of the PV is greater than the cost, $x$.

If investors forecast an Invest signal next period followed by the no invest signal then an investor who invests $x$ for fraction q expects to receive $q p V+(1-p)(1-q) q p V$, that is, if it pays off in the first attempt (prob $p$ ) they get $q V$ and if it pays off on the second attempt (prob $(1-p) p$ ) they get a fraction $q$ of what doesn't go to the second investor 
$(1-q) V$. Therefore, the first investors would invest as long as $x \leq q p V+(1-p)(1-q) q p V$.

And if investors forecast infinite Invest signals then the first investor would invest as long as $x \leq q p V+(1-p)(1-q) q p V+(1-p)(1-p) p q(1-q)(1-q) V+\ldots=q p V \sum_{i=0}^{\infty}(1-p)^{i}(1-q)^{i}$ which equals $p V \frac{q}{1-(1-p)(1-q)}$.

It might then seem that as long as $(1-p)(1-q) q p V>0$ that some parameters would result in a world where $x \geq q p V$ but $x \leq q p V+(1-p)(1-q) q p V$ so investors would invest only if they forecasted future investment, and thus there would be financing risk. Or $x \geq q p V$ but $x \leq p V \frac{q}{1-(1-p)(1-q)}$, which would again result in financing risk.

However, this is not correct.

If $x \geq q p V$ the $q$ endogenously increases until the first round investor invests $\left(x \leq q^{\prime} p V\right)$ or $q$ or hits 1 . That is, firms that are about to fail because the cant get funding increase the fraction they are willing to give to get funded. Thus, the first period investor will only not invest in equilibrium if $x \geq p V$. However, if this is true then $x \geq p V \frac{q}{1-(1-p)(1-q)}$ because $\frac{q}{1-(1-p)(1-q)} \leq 1 \forall 0 \leq q \leq 1$. Thus, if the first round investor will not invest in the No-Invest equilibrium then he wont invest in the Invest equilibrium, and vice versa.

Therefore, there is no financing risk in this model - investors either always invest or never do. In order to get rational equilibrium financing risk the forecast of no financing tomorrow must fundamentally alter the outcome of the project in some way. This is what the model we present in this paper does.

\section{A3. Proof of Proposition 1:}

Under the belief that future investors will not invest if the signal $s(t+1)=0$ and otherwise will invest, then if the the signal $s(t)=1$ then the expected project NPV is

$$
\left.\Pi\right|_{s(t)=1}=\frac{\gamma_{a}[\theta V(1)+(1-\theta) V(0)]-x(1+r)}{(1+r)-\theta\left(1-\gamma_{l}-\gamma_{a}\right)}
$$

It is only rational for a $\mathrm{VC}$ to forecast that a future $\mathrm{VC}$ will invest even if the project has not improved if $\left.\Pi\right|_{s(t+1)=1} \geq 0$, or, given the stationarity in the model $\left.\Pi\right|_{s(t)=1} \geq 0$.

If, on the other hand, the signal $s(t)=0$ and the investors believe that future investors will not invest if $s(t+1)=0$ then the expected project NPV is 


$$
\begin{aligned}
&\left.\Pi\right|_{s(t)=0}=\left[\frac{(1-\phi)\left(1-\gamma_{l}-\gamma_{a}\right)}{1+r}\right] \frac{\gamma_{a}[\theta V(1)+(1-\theta) V(0)]-x(1+r)}{(1+r)-\theta\left(1-\gamma_{l}-\gamma_{a}\right)} \\
&+\left[\frac{\gamma_{a}[(1-\phi) V(1)+\phi V(0)]}{1+r}-x\right]
\end{aligned}
$$

But it is only rational to forecast other VCs will not invest if $\left.\Pi\right|_{s(t+1)=0}<0$, or given the stationarity in the model if $\left.\Pi\right|_{s(t)=0}<0$.

Given these equations then it follows directly that $\left.\Pi\right|_{s(t)=1}>\left.\Pi\right|_{s(t)=0}$, under the belief that $s(t+1)=0$ implies no future investment, and there are three possibilities. First, if $\left.\Pi\right|_{s(t)=1}>\left.\Pi\right|_{s(t)=0} \geq 0$ then the expected profit from investing when $s(t+1)=0$ is positive and therefore it is not rational to believe that investors will not invest when $s(t+1)=0$. In this case rational investors believe the firm will always get investment. Second, if $0>\left.\Pi\right|_{s(t)=1}>\left.\Pi\right|_{s(t)=0}$ then independent of the signal the NPV is negative investors will never invest. Third, if $\left.\Pi\right|_{s(t)=1} \geq 0>\left.\Pi\right|_{s(t)=0}$ then the signal determines whether or not the expected profit from investing is NPV positive.

It is possible for both inequalities $\left.\Pi\right|_{s(t)=1} \geq 0>\left.\Pi\right|_{s(t)=0}$ to simultaneously hold as long as $\gamma_{a}[\theta V(1)+(1-\theta) V(0)]>x(1+r)$ and

$$
\frac{\gamma_{a}[\theta V(1)+(1-\theta) V(0)]-x(1+r)}{(1+r)-\theta\left(1-\gamma_{l}-\gamma_{a}\right)}<\frac{x(1+r)-\gamma_{a}[(1-\phi) V(1)+\phi V(0)]}{(1-\phi)\left(1-\gamma_{l}-\gamma_{a}\right)}
$$

as long as $V(0)$ is low enough relative to $V(1)$ and $\phi$ and $\theta$ are high enough. For such parameters the expected profit from investing when $s(t)=1$ is positive and the expected profit from investing when $s(t)=0$ is negative. So rational investment depends on the signal. The equilibrium choice is to invest when $s(t)=1$ and not to invest when $s(t)=0$ given the beliefs of other agents. ${ }^{26}$ Thus, there is are two symmetric pure strategy subgame perfect Bayesian equilibria in which every investors decision to invest depends on the signal.

\section{A4. Proof of Proposition 2:}

We begin by solving for the profit functions for any level of commitment. This can be done using an iterative expansion process or by simply multiplying each potential outcome by the probability it occurs. For an investment with $N$ periods of committed capital, $n=N$, there could be success, failure, or the commitment could run out. The

\footnotetext{
${ }^{26}$ Though, of course, other beliefs could generate alternative equilibria.
} 
value of the success or what happens if the commitment runs out depend on the state when it occurs. So for any $N \geq 2$

$$
\begin{aligned}
\left.\Pi\right|_{s(t)} ^{n=N}=\left(\frac{\gamma_{a} V(1)}{1+r}\right. & -x) \sum_{i=0}^{N-2} \frac{\left(1-\gamma_{l}-\gamma_{a}\right)^{i}}{(1+r)^{i}} \\
& +\left.\Pi\right|_{s(t+N)=1} ^{n=0} \frac{\left(1-\gamma_{l}-\gamma_{a}\right)^{N}}{(1+r)^{N}}\left[\begin{array}{ll}
Z & Y
\end{array}\right] S^{N-1}\left[\begin{array}{l}
1 \\
0
\end{array}\right] \\
& +\left(\frac{\gamma_{a} V(1)}{1+r}-x\right) \frac{\left(1-\gamma_{l}-\gamma_{a}\right)^{N-1}}{(1+r)^{N-1}}\left[\begin{array}{ll}
Z & Y
\end{array}\right] S^{N-1}\left[\begin{array}{l}
1 \\
0
\end{array}\right] \\
& +\left(\frac{\gamma_{a} V(0)}{1+r}-x\right) \frac{\left(1-\gamma_{l}-\gamma_{a}\right)^{N-1}}{(1+r)^{N-1}}\left[\begin{array}{ll}
Z & Y
\end{array}\right] S^{N-1}\left[\begin{array}{l}
0 \\
1
\end{array}\right]
\end{aligned}
$$

where $Z=s(t) \theta+(1-s(t))(1-\phi)$ and $Y=s(t)(1-\theta)+(1-s(t)) \phi$ and $S$ is the transition matrix (equation (1)). The first term accounts for the possibility that the project might succeed in any period and generate a value $V(1)$ because of the future commitment, and investors must pay $x$ until it succeeds, or fails. The second term accounts for the possibility that after $\mathrm{N}$ periods the firm has neither progressed nor failed. If the state is $s(t+N)=0$ then the project is worth zero at that point but if $s(t+N)=1$ then the project is worth $\left.\Pi\right|_{s(t+N)=1} ^{n=0}=\left.\Pi\right|_{s=1} ^{n=0}$, (because of stationarity) which must be multiplied by the probability that the state is $s(t+N)=1$, which is $\left[\begin{array}{ll}Z & Y\end{array}\right] S^{N-1}\left[\begin{array}{l}1 \\ 0\end{array}\right]$, which depends on the initial state. The final two terms account for the possibility that for all N-1 investments the project neither succeeds nor fails, and then the projects succeeds with the $N^{\text {th }}$ investment. Whether this success generates $V(1)$ or $V(0)$ depends on the state in the $N^{\text {th }}$ period. The probability that it is $s(t+N)=1$ is $\left[\begin{array}{ll}Z & Y\end{array}\right] S^{N-1}\left[\begin{array}{l}1 \\ 0\end{array}\right]$, and the probability that the $N^{t h}$ period state is $s(t+N)=0$ is $\left[\begin{array}{ll}Z & Y\end{array}\right] S^{N-1}\left[\begin{array}{l}0 \\ 1\end{array}\right]$.

A project faces financing risk even with a commitment of $n=N$ as long as $\left.\Pi\right|_{s(t+N)=0} ^{n=N}<$ 0 . Any particular level of commitment may not make the project NPV positive. However, 
the limit of $\left.\Pi\right|_{s(t)=0} ^{n=N}$ as $N->\infty$ is

$$
\left.\Pi\right|_{s(t)=0} ^{n=\infty}=\frac{\gamma_{a} V(1)-(1+r) x}{(1+r)-\left(1-\gamma_{l}-\gamma_{a}\right)}
$$

which is just the value of the project without financing risk, and thus clearly NPV positive. Therefore, there is some $\bar{N}<\infty$ such that $\left.\Pi\right|_{s(t)=0} ^{n=\bar{N}}>0$. So investors will make an investment of $\bar{N} x$ regardless of the signal $s(t)$. So the project is no longer impacted by financing risk.

\section{A5. Proof of Proposition 3:}

With complete contracts we know from Proposition 2 that the value of the project with commitment is equation (A12).

With incomplete contracts the profit functions with commitment for $n=N \geq 2$ is

$$
\begin{aligned}
\left.\Pi\right|_{s(t)} ^{n=N}=\left(\frac{\gamma_{a} V(1)}{1+r}-\right. & x) \sum_{i=0}^{N-2} \frac{\left(1-\gamma_{l}-\gamma_{a}\right)^{i}}{(1+r)^{i}} \\
& +\left.\Pi\right|_{s(t+N)=1} ^{n=0} \frac{\left(1-\gamma_{l}-\gamma_{a}\right)^{N}}{(1+r)^{N}}\left[\begin{array}{ll}
Z & Y
\end{array}\right] S^{N-1}\left[\begin{array}{l}
1 \\
0
\end{array}\right] \\
& +\left(\frac{\gamma_{a} V(1)}{1+r}-x\right) \frac{\left(1-\gamma_{l}-\gamma_{a}\right)^{N-1}}{(1+r)^{N-1}}\left[\begin{array}{ll}
Z & Y
\end{array}\right] S^{N-1}\left[\begin{array}{l}
1 \\
0
\end{array}\right] \\
& +\left(\frac{\gamma_{a} V(0)}{1+r}-x\right) \frac{\left(1-\gamma_{l}-\gamma_{a}\right)^{N-1}}{(1+r)^{N-1}}\left[\begin{array}{ll}
Z & Y
\end{array}\right] S^{N-1}\left[\begin{array}{l}
0 \\
1
\end{array}\right] \\
& -\frac{x \gamma_{l}}{1+r} \sum_{i=0}^{N-2}\left[\frac{\left(1-\gamma_{l}-\gamma_{a}\right)^{i}}{(1+r)^{i}} \sum_{j=0}^{N-2-i} \frac{1}{(1+r)^{j}}\right]
\end{aligned}
$$

where $Z=s(t) \theta+(1-s(t))(1-\phi)$ and $Y=s(t)(1-\theta)+(1-s(t)) \phi$ and $S$ is the transition matrix (equation (1)). For $n<2$ there is no difference between complete and incomplete contracts.

The difference between complete and incomplete contracts is (A14) - (A12)

$$
-\frac{x \gamma_{l}}{1+r} \sum_{i=0}^{N-2}\left[\frac{\left(1-\gamma_{l}-\gamma_{a}\right)^{i}}{(1+r)^{i}} \sum_{j=0}^{N-2-i} \frac{1}{(1+r)^{j}}\right]<0
$$


Thus, the value of committing and extra $x$ with incomplete contracts is less than with complete contracts. So incomplete contracts reduce the value of committing more money. Furthermore, the derivative of equation (A14) with respect to $\gamma_{l}$ or $x$ is negative. Therefore, the reduction in value from incomplete contracts is larger for projects with larger $\gamma_{l}$ or more costly experiments. Thus, the reduction in value is larger for more 'innovative' firms - those where the option to shut down is more valuable.

The limit of $\left.\Pi\right|_{s(t)} ^{n=N}$ with incomplete contracts as $N->\infty$ is

$$
\left.\Pi\right|_{s(t)} ^{n=\infty}=\frac{\gamma_{a} V(1)-(1+r) x-\gamma_{l} x / r}{(1+r)-\left(1-\gamma_{l}-\gamma_{a}\right)}
$$

which may or may not be positive depending on the size of $x / r$ and the probability of failure. Thus, for some firms with large enough $\gamma_{l}$, committing enough to eliminate financing risk will be NPV negative. Thus, for these firms committing some amount less than infinity will make the project NPV negative. 